Susi K. Frank

\title{
,Multinationale Sowjetliteratur' und ihre Agenten auf dem Buchmarkt zwischen Ost und West: Der Fall Ajtmatov
}

Der folgende Beitrag ist den deutsch-sowjetischen Literaturbeziehungen in Ost- und Westberlin bzw. -deutschland gewidmet sowie deren Konkurrenz und Verflechtungen im jeweiligen kulturpolitischen Kontext. ${ }^{1}$ Dabei geht es insbesondere um Ostberlin als Bühne sowjetischer Literaturpolitik und darum, was davon wie im Westen rezipiert und aus der westlichen Perspektive modifiziert wurde. Die generelle Frage ist die nach den spezifischen Modellierungen und Kanonisierungen der russischsprachigen Gegenwartsliteratur durch die jeweilige Publikations- und Verlagspolitik: Wie unterschied sich die russisch-sowjetische Literatur des Westens von der russisch-sowjetischen Literatur des Ostens? Da gibt es natürlich viel Erwartbares, wie den Fokus des Westens auf die Moderne im Gegensatz zur Ausrichtung des Ostens auf Traditionen des (politisch engagierten) Realismus, oder den Umstand, dass Autoren im Exil - wie Nabokov und später auch Solženicyn - zunächst nur im Westen publiziert wurden. Aber es werden auch viele Parallelen erkennbar und manchmal unerwartet enge Verbindungen z. B. in Hinblick auf Übersetzungen und Verlagslizenzen. Die Entwicklung und Festigung der jeweiligen literaturpolitischen Positionen war nach dem Mauerbau in Zeiten des sich zuspitzenden Kalten Krieges in vollem Gang und beförderte die literarische und öffentliche Aufmerksamkeit aufeinander, insbesondere das Interesse des Westens für russisch-sowjetische Literatur, die im Osten sowieso als Maßstab galt. Eine andere wichtige Frage ist, welche ästhetisch-stilistischen Wege von jungen Autor:innen selbst eingeschlagen und welche Strategien der Selbstpositionierung in einem sowjetischen/ multinationalen Kanon genutzt wurden. Womit konnte Interesse geweckt, womit Anerkennung gewonnen werden?

In Hinblick auf neue ästhetische Tendenzen in den 1960er Jahren und auf die Verflechtungen und Entzweiungen in der Rezeption der russisch-sowjetischen Literatur zwischen Ost und West und die Konkurrenz bei Übersetzung und Kanonisierung in DDR und BRD ist der Fall des kirgisisch-sowjetischen Prosaautors Čingiz Ajtmatov besonders interessant. Sein Rezeptionsschicksal, dem dieser Aufsatz nachgeht, kann trotz der Sonderstellung, die der besonders erfolgreiche Autor einnahm, als exemplarisch angesehen werden in Hinblick auf die Spezifik der Rezeption der sowjetischen

1 Ich bedanke mich herzlich bei Sabine Wolf vom Archiv der Akademie der Künste Berlin für die unkomplizierte Unterstützung in Zeiten der COVID-Pandemie; sowie bei Gulzat Egemberdieva für Hilfe beim Finden von Publikationen in Kyrgystan und bei Andreas Tretner für wichtige Hinweise auf Übersetzerbiographien und die Community der sowjetischen Gäste in Ostberlin. 
Literatur in Ost und West, die Programmatik der Promotion von Seiten der sowjetischen Literaturpolitik und die literarischen Strategien der Selbstpositionierung eines Autors, der 1960 als Vertreter der multinationalen Sowjetliteratur im Osten auf den Plan trat und etwas später im Westen als neue Stimme der Weltliteratur aus der hintersten eurasischen Peripherie gefeiert wurde.

Čingiz Ajtmatov war in den 1960er Jahren nur einmal in Berlin, und zwar 1968 in Ostberlin. Westberlin besuchte er erst 1983, bei seinem zweiten Besuch in Deutschland. Aber da er bereits vor seinem ersten Besuch schon in Westdeutschland verlegt worden war, ist auch der Blick auf den ersten Aufenthalt und überhaupt auf die Anfänge der deutschen Ajtmatov-Rezeption seit 1960 und ihre jeweiligen kulturellen Kontexte aufschlussreich.

\section{Multinationale Sowjetliteratur: Literaturpolitische Doktrin und Rahmen der Rezeption russisch- sowjetischer Literatur in der DDR}

Sowjetliteratur war seit dem 1. Allunionskongress der Sowjetschriftsteller 1934 in Moskau, der mit vierzig namhaften Autoren aus dreizehn westlichen Ländern auch eine internationale Großveranstaltung (582 Delegierte insgesamt) war, das zentrale literaturpolitische Projekt der Sowjetunion. Damals hatte Gor'kij in seiner programmatischen Eröffnungsrede verkündet:

[...] die sowjetische Literatur [ist] nicht nur eine Literatur der russischen Sprache, sondern eine Allunionsliteratur. [...] [Wir haben kein Recht,] das literarische Schaffen der nationalen Minderheiten nur deshalb zu ignorieren, weil wir in der Mehrzahl sind. Der Wert der Kunst wird nicht an der Quantität, sondern an der Qualität gemessen. Wenn es bei uns in der Vergangenheit den Giganten Puškin gab, so darf man daraus nicht schlussfolgern, die Armenier, Grusinier, Tataren, Ukrainer und anderen Völker seien nicht fähig, große Meister der Literatur, der Musik, der Malerei und der Baukunst hervorzubringen. ${ }^{2}$

2 Maksim Gor'kij: Über sowjetische Literatur. Übersetzt von Ingeborg Schröder, in: Hans-Jürgen Schmitt, Godehard Schramm (Hrsg.): Sozialistische Realismuskonzeptionen. Dokumente zum 1. Allunionskongress der Sowjetschriftsteller, Frankfurt a. M. 1974, 51-84, hier: 76. Russisch: „Далее, я считаю необходимым указать, что советская литература не является только литературой русского языка, это - всесоюзная литература. Так как литераторы братских нам республик, отличаясь от нас только языком, живут и работают при свете и под благотворным влиянием той же идеи, объединяющей весь раздробленный капитализмом мир трудящихся, - ясно, что мы не имеем права игнорировать литературное творчество нацменьшинств только потому, что нас больше. Ценность искусства измеряется не количеством, а качеством. Если у нас в прошлом - гигант Пушкин, отсюда еще не значит, что армяне, грузины, татары, украинцы и прочие племена не способны дать величайших мастеров литературы, музыки, живописи, 
Nationale Vielfalt wurde hier in doppeltem Sinn in einem weltliterarischen Horizont gedacht: erstens, weil die Multinationalität der Sowjetliteratur im Prinzip integrativ und expansiv, also unbegrenzt bzw. global erweiterbar gesehen wurde, da es darum ging, die vom Kapitalismus in nationale Einzelinteressen zerstückelte Welt im Zeichen des Sozialismus zu einen; und zweitens, weil es darum ging, Sowjetliteratur in einer weltliterarischen historischen Entwicklung zur verstehen: als Speerspitze auf dem Weg zum sozialistischen Realismus und als Erbin der gesamten vorgängigen Weltliteratur, in deren Feld die sowjetischen Autoren sich literarisch und mit dem ethischen Anspruch eines universell gültigen Humanismus etablieren sollten. Aber die ,Speerspitze“ implizierte ihrerseits eine Asymmetrie. In seiner programmatischen Rede versuchte Gor'kij, der Vision der Vielstimmigkeit mit allen Mitteln der Rhetorik gerecht zu werden. Dennoch wird bereits in dem hier angeführten Zitat deutlich, dass dieser Programmatik eine Hierarchie eingeschrieben war zwischen der russischen Literatur als ,älterem Bruder', als ,Vorbild‘ und als einer der bereits seit langem etablierten ,Weltliteraturen' einerseits und andererseits den Literaturen der nationalen Minderheiten, denen bislang vor allem das Potential zu ähnlichen Entwicklungen zugebilligt werden sollte. Mit der Politik eines „,affirmative action empire“, wie Terry Martin die sowjetisch-stalinistische Politik der Multinationalität 2001 genannt hat, ${ }^{3}$ wurden zugleich nationale (und internationalistische) kulturelle und literarische Tendenzen in den Republiken gewaltsam ausgelöscht und als sowjetische brachial (wieder)errichtet. Dabei wurden die Literaturen als zum großen Teil künstlich geschaffene nationalliterarische Einheiten nach sozialistischen Maßgaben neu etabliert. Damals, auf dem Kongress 1934 wie auch in den späteren umfassenden institutionellen Umsetzungen des Programms, manifestierte sich die Hierarchie z. B. darin, dass auch institutionell stets unterschieden wurde zwischen russischer Literatur und den ,Literaturen der Völker der Sowjetunion'. Die russische Kultur bzw. Literatur wurde in diesem Zusammenhang nie als eine unter den anderen ,nationalen' gewertet. Schon auf dem Kongress 1934 traten Repräsentanten aller alten und neuen Nationalliteraturen auf, aber die russischen Sprecher vertraten die Literatur an sich bzw. die sowjetische Literatur allgemein.

Dass Gor'kij damals im selben Referat Literatur und Mythos auch in einem anthropologischen Zusammenhang verstand, war demgegenüber eine Strategie der Egalisierung und ermöglichte auch den neugeschaffenen Nationalliteraturen, für die

\footnotetext{
зодчества. Не следует забывать, что на всем пространстве Союза Социалистических Республик быстро развивается процесс возрождения всей массы трудового народа ,к жизни честной человеческой‘, к свободному творчеству новой истории, к творчеству социалистической культуры.“ Maksim Gor'kii: Doklad A. M. Gor'kogo o sovetskoj literature, in: Pervyj vsesojuznyj s'ezd sovetskich pisatelej 1934. Stenografičeskij otčet, Moskau 1934, 5-19, hier: 15. Auch abgedruckt in: Maksim Gor'kij: Sobranie sočinenij v devjati tomach, Moskau 1953, Bd. 27.

3 Terry Martin: The Affirmative Action Empire. Nations and Nationalism in the Soviet Union, 19231939, Ithaca/London 2001.
} 
zum Teil erst jetzt Literatursprachen geschaffen wurden, ein nationales Erbe zu definieren, das ebenfalls als Teil der Weltliteratur sichtbar wurde und als ,Schatz', auf den ,kritisch aneignend“ und gestalterisch zurückgegriffen werden konnte:

Die Mythe ist eine Schöpfung dichterischer Phantasie. Etwas erdichten heißt, aus der Gesamtheit der realen Gegebenheiten den Hauptsinn extrahieren und ihn in einer Gestalt verkörpern - so entsteht der Realismus. Wenn man aber zu dem extrahierten Sinn der realen Gegebenheiten das Gewünschte und Mögliche hinzufügt, d.h. nach der Logik einer Hypothese zu Ende denkt und dadurch die Gestalt ergänzt, erhält man jene Romantik, die der Mythe zugrunde liegt und äußerst nützlich ist, weil sie die Entfaltung eines revolutionären Verhältnisses zur Wirklichkeit fördert, das die Welt praktisch verändert. ${ }^{4}$

Nationale Vielfalt, die Konstruktion eines nationalen Erbes und der ,kritisch'schöpferische Umgang damit waren also seit den 1930er Jahren neben der Doktrin des sozialistischen Realismus weitere wichtige Normen sowjetischer Literaturpolitik.

Zeitschriften-, Verlags- und Übersetzungspolitik fungierten als zentrale Instrumente der nationalen und internationalen Umsetzung des Projekts ,Sowjetliteratur'. Und eines der effektivsten Formate in diesem Zusammenhang waren Anthologien: nationale Anthologien, und - seit Beginn der Nachkriegszeit - zunehmend auch Anthologien der ,Sowjetliteratur‘. In der Komposition solcher Anthologien lässt sich ablesen, dass für ,nationale Autoren' die Aufnahme einen transnationalen Kanonisierungsschritt bedeutete.

\section{Multinationale Sowjetliteratur auf der Berliner Bühne}

Auf der Berliner Bühne der 1960er Jahre manifestierte sich die verordnete Multinationalität der Sowjetliteratur darin, dass im Rahmen des festgelegten Prozentsatzes von $40 \%$ an sowjetischen Autoren unter den ausländischen Gästen stets Autoren aus den nicht-russischen Sowjetrepubliken vertreten waren: ${ }^{5}$ So nahm an dem Internationalen Colloquium zum Thema Die Existenz zweier deutscher Staaten und die Lage der Literatur 1964 der vollkommen unbekannte, aber als nationaler Literaturfunktionär

\footnotetext{
4 Gor'kij: Über sowjetische Literatur (Anm. 2), 64. Russisch: „Миф - это вымысел. Вымыслить значит извлечь из суммы реально данного основной его смысл и воплотить в образ - так мы получили реализм. Но если к смыслу извлечений из реально данного добавить- домыслить, по логике гипотезы - желаемое, возможное и этим еще дополнить образ, - получим тот романтизм, который лежит в основе мифа и высоко полезен тем, что способствует возбуждению революционного отношения к действительности, отношения, практически изменяющего мир.“ Gor'kij: O sovetskoj literature (Anm. 2), 10.

5 Ich habe die folgenden Angaben der Einreisestatistik des Deutschen Schriftstellerverbands entnommen und bedanke mich bei Lukas Regeler für die Unterstützung bei der Datenermittlung.
} 
wichtige tadschikische Autor Fateh Nijasi ( $\left.{ }^{\star} 1914\right)$ teil. ${ }^{6}$ Dieser wurde auch zum Internationalen Schriftstellertreffen 1965 in Berlin und Weimar eingeladen, dessen Teilnehmer fast zur Hälfte aus nichtrussischen Sowjetrepubliken kamen. Darunter: der kirgisische Dichter Temirkul Umetaliev ( ${ }^{\star} 1908$ ), der georgische Dichter Irakli Abashidze ( $\left.{ }^{\star} 1909\right)$, einer der ganz wenigen Repräsentanten einer sowjetischen Nationalliteratur, der schon auf dem Sowjetischen Kongress 1934 aufgetreten war und der die Stalinistischen Säuberungen überlebt hatte, der ukrainische Prosaiker Oles Hontschar ( $\left.{ }^{\star} 1918\right)$, der vergleichsweise junge ukrainische Dichter Ivan Drač ( $\left.{ }^{\star} 1934\right)$ sowie der litauische Dichter Justinas Marcinkievicius (*1930). Alle diese Autoren galten als ideologisch linientreu und waren neben ihrer literarischen Tätigkeit immer zugleich als Literaturfunktionäre tätig. Einige von ihnen, so zeigen die Archivdokumente, wurden immer wieder nach Berlin entsandt, insbesondere die russischen Autoren: so z. B. Konstantin Fedin, Vorsitzender des Sowjetischen Schriftstellerverbands und langjähriger Vorsitzender der Deutsch-Sowjetischen Freundschaftsgesellschaft (seit 1958), Georgij Markov, der beim Colloquium 1964 dabei war und über Jahre als Auslandsberichterstatter des sowjetischen Schriftstellerverbands fungierte, Daniil Granin ( $\left.{ }^{\star} 1919\right)$, Vorstandsmitglied des Schriftstellerverbands der UdSSR, der 1969 für den Ausschluss von Aleksandr Solženicyn aus demselben stimmte, Vadim Koževnikov ( $\left.{ }^{\star} 1909\right)$, Herausgeber der Zeitschrift Znamja, dem man später nachsagte, er hätte das Manuskript von Vasilij Grossmans Leben und Schicksal dem KGB weitergereicht, Lev Ginzburg ( $\left.{ }^{\star} 1921\right)$, der deutsche Literatur von Des Knaben Wunderhorn bis Peter Weiss übersetzte und bei zahlreichen internationalen Schriftstellertreffen Gast in Ostberlin war, oder auch Vladimir Steženskij, Germanist und Übersetzer aus dem Deutschen, der unter anderem über Wolfgang Koeppen arbeitete, seine Werke übersetzte und seine russische Ausgabe mit einer Einleitung versah. Da Steženskij beim sowjetischen Schriftstellerverband für die Auslandskontakte mit Autor:innen in Ost und West und insbesondere für die deutschen zuständig war, war er unten allen genannten derjenige, der sehr regelmäßig und wohl am häufigsten in Berlin war. ${ }^{7}$ Der Titel seines 1978 in Moskau in Ko-Autorschaft mit Lidija Černaja erschienenen Buches Literaturnaja bor'ba $v$ FRG (dt. Literaturkampf in der $\mathrm{BRD})^{8}$, welches einen politisch orientierten Überblick über die Entwicklung der westdeutschen Literatur in der Nachkriegszeit gibt, macht die Ostberliner Perspektive

6 Vgl. dazu Elke Scherstjanoj (Hrsg.): Zwei Staaten, zwei Literaturen? Das internationale Kolloquium des Schriftstellerverbandes in der DDR, Dezember 1964. Eine Dokumentation, München 2008, 199.

7 In Russland ist Steženskij heute noch als Autor des immer wieder aufgelegten Soldatskij denvnik. Voennye stranicy (Soldatentagebuch. Aufzeichnungen aus dem Krieg) über seine Zeit als Übersetzer und Aufklärer/Spion an der Front bekannt, dessen jüngste Neuauflage 2005 herauskam. Ich danke Andreas Tretner für den Hinweis, dass Vladimir Steženskij sich bei den Berliner Kolleg:innen großer Beliebtheit erfreute und auch jenseits der Begegnungen vor Ort etwa mit Christa Wolf im Briefwechsel stand.

8 Vladimir Steženskij, Ljudmila Černaja: Literaturnaja bor’ba v FRG. Poiski. Protivorečija. Problemy, Moskau 1978. 
vollends explizit: Aus sowjetischer Perspektive wurde Berlin als Front der sowjetischen Literaturpolitik im Kalten Krieg verstanden.

Auf Čingiz Ajtmatov, der 1968 nicht als quoten-nationaler Teilnehmer eines Autorentreffens nach Berlin kam, sondern als Einzelgast des Verlages Volk und Welt Teile des Augusts und den September 1968 in Berlin verbrachte, trifft das Gesagte auch zu: Ajtmatov war ebenfalls nicht nur Schriftsteller, sondern auch Literatur- bzw. Parteifunktionär. In der Sowjetunion war er damals bereits durch Staatspreise dekoriert und hatte hohe Ämter inne. Unter den oben genannten nicht-russischen, sogenannten ,nationalen' Autoren ist Ajtmatov der einzige, der transnational und international rezipiert und kanonisiert wurde.

Um mich der Kanonisierung Ajmatovs in Ost- und Westdeutschland vor und nach seinem ersten Auftreten auf der Ost-Berliner Bühne und in Deutschland überhaupt anzunähern, möchte ich zunächst über den Status der Sowjetliteratur im Verlag Volk und Welt und dessen literarische Programmatik als Verlag für Weltliteratur sprechen. Anschließend werde ich den Werdegang Ajtmatovs als Hauptvertreter der kirgisischen Sowjetliteratur beleuchten und auch auf die vor 1968 liegende Etappe seiner deutschdeutschen und internationalen Rezeption eingehen. All das steht, erstens, im Zeichen der Frage danach, wie in den späten 1950er und 1960er Jahren ein Autor aus Kirgisien nationale, sowjetische und internationale Anerkennung finden konnte, und betrifft, zweitens, den Vergleich der Rezeption von Ajmatov als Autor im Kontext des sowjetischen multinationalen Weltliteraturprojekts mit seiner Rezeption im Westen.

\section{Der Verlag Volk und Welt}

Der Verlag Volk und Welt wurde 1947 gegründet als ,Leitverlag‘ für Internationale Gegenwartsliteratur mit Schwerpunkt Sowjetunion, aber zuständig für die ,gesamte Weltliteratur‘. Im selben Jahr wurde als eigener Verlag der Gesellschaft für DeutschSowjetische Freundschaft der Verlag Kultur und Fortschritt gegründet, der ausschließlich sowjetische Gegenwartsliteratur publizierte und 1964 in den viel größeren Volk und Welt Verlag eingegliedert wurde. ${ }^{9}$ Neben dem schon 1945 gegründeten AufbauVerlag war Volk und Welt der zweite große Literaturverlag der DDR. Während Aufbau auf anspruchsvolle deutsche Literatur und Klassiker der Weltliteratur ausgerichtet war und in den ersten zwei Jahrzehnten neben Brecht, Döblin, Feuchtwanger und Seghers auch Proust, Hemingway, Sartre und auch Kafka publizierte, lag der Schwerpunkt von Volk und Welt auf der internationalen Gegenwartsliteratur. Russische Literatur

9 Da dies offensichtlich zum Politikum hätte werden können, weil es den gesellschaftlichen Einfluss der Deutsch-Sowjetischen Freundschaftsgesellschaft zu beeinträchtigen drohte, erhielt diese fortan eine Million Mark pro Jahr Entschädigung. Vgl. Simone Barck, Siegfried Lokatis (Hrsg.): Fenster zur Welt. Eine Geschichte des DDR-Verlags Volk und Welt, Berlin 2003, 35 ff. 
wurde in beiden Verlagen publiziert, bei Aufbau zunächst Gor'kij, Tolstoj, Puškin, aber auch Anton Makarenko (Der Weg ins Leben, ru. 1927, dt. 1950) und Leonid Solov'ev mit dem orientalistischen Schelmenroman Chodža Nasreddin (Teil 1 1942). Bei Volk und Welt war der Fokus noch zeitgenössischer und internationaler bzw. ,Welt'-offener. Volk und Welt hatte über Jahrzehnte mehr als zwanzig Lektorate und publizierte insgesamt über 5000 Titel mit einer durchschnittlichen Auflagenhöhe von 17000 Exemplaren. Die multinationale Programmatik in ihrer sowjetischen Definition lässt sich 1:1 in den Programmen von Volk und Welt (und Kultur und Fortschritt) wiederfinden. Das über die Praxis der Autorenentsendung und die ,Quoten-Nationalen“ Gesagte trifft - und dies ist nicht als Vorurteil gemeint - auch auf die Publikationspraxis von Volk und Welt zu. Nicht-russische Autoren mussten berücksichtigt werden, und sie wurden berücksichtigt. Unter der Leitung von Leonhard Kossuth, der rund dreißig Jahre, von 1959-1989, für das Ressort für Sowjetliteratur verantwortlich war, ${ }^{10}$ und Ralph Schröder, Slavist von der Uni Leipzig, der nach einer Zurücksetzung und Zuchthausstrafe 1966 als Lektor in den Verlag kam und seine Programmtätigkeit da als ,angewandte Literaturgeschichtsschreibung، auffasste, wurde die multinationale Sowjetliteratur programmatisch als zentraler Bestandteil eines weltliterarischen Programms berücksichtigt. Insbesondere mithilfe von Reihen und Anthologien wurde diese multinationale Ausrichtung in globalem Horizont zelebriert und auch die von Gor'kij proklamierte Auf- und Gleichwertung von Folklore. Letztere manifestierte sich z. B. in den gattungsspezifischen Regionalanthologien von Lyrik über Prosa bis zum Märchen und zur Volksepik.

Zunehmend versuchte man, Lektoren mit Expertise für einzelne Nationalliteraturen zu finden. In einigen Fällen gelang dies - wie z. B. im Fall von Kristiane Lichtenfeld, Übersetzerin aus dem Russischen und Polnischen, die zusätzlich das Georgische erlernte und praktisch alle im Verlag erschienen georgischen Werke ins Deutsche übersetzte $^{11}$ - in vielen Fällen sah die Praxis des Übersetzens aber genauso aus wie in der Sowjetunion: Die Übersetzer:innen, konnten` aus allen Sprachen übersetzen, weil sie mit Interlinearübersetzungen als Vermittlung zum Original arbeiteten. Schon 1962 hatte Efim Etkind diesbezüglich ironisch vom ,universalen Übersetzer' gesprochen, der auf der Basis von Interlinearübersetzungen aus jeder beliebigen Sprache der Welt, die er nicht kennt und nicht lesen kann, Texte aus Kulturen übersetzen kann, von denen

10 Vgl. Leonhard Kossuth: Sowjetliteratur und ihre Multinationalität, in: ebd., 57-61. Sowie Leonhard Kossuth: Volk und Welt. Autobiographisches Zeugnis von einem legendären Verlag, Berlin 2002. 11 Als Überblick über ihre Übersetzungen aus dem Georgischen erschien 2020 im Nora-Verlag Christiane Lichtenfeld: Georgien zu Wort kommen lassen. Erfahrungen und Erfolge einer Literaturübersetzerin, Berlin 2020. Direkte Übersetzerinnen aus nichtrussischen Nationalliteraturen waren zudem aus dem Litauischen Irene Brewing und aus dem Lettischen Welta Ehlert. Vgl. zu dieser Problematik auch Leonhard Kossuth: Sowjetliteratur und ihre Multinationalität, in: Barck/Lokatis (Hrsg.): Fenster zur Welt (Anm. 9), 57-61, hier: 60. 
er keine Ahnung hat. ${ }^{12}$ Die Rolle des Übersetzers barg in diesem spezifischen Kontext ein höchst komplexes strategisches Potential: einerseits in Hinblick auf gewisse Lizenzen, die sich Übersetzer gelegentlich erlauben konnten, andererseits hinsichtlich der Möglichkeit für (latent) repressierte Autoren als Übersetzer doch im Bereich der Literatur Anstellung und Broterwerb zu finden. ${ }^{13}$ Beachtenswert ist dabei auch, dass bestimmte Teile der zu übersetzenden Corpora, wie z. B. das protoliterarische Erbe der Nationalliteraturen, fast nie von Vertretern dieser Nationalliteraturen, sondern zumeist von russischen und oft von jüdischen russischsprachigen Autoren übersetzt wurden. ${ }^{14}$ Die meisten bei Volk und Welt publizierten Texte von nicht-russischen Autoren wurden aus dem Russischen übersetzt. Wobei hinzuzufügen ist, dass viele der zu übersetzenden Texte der nicht-russischen Autoren auch auf Russisch geschrieben waren, da Russisch nicht nur als lingua franca in der Sowjetunion und im politischen Einflussbereich derselben fungierte, sondern auch als einzige Sprache, in der Autoren auf transnationale Anerkennung und internationale Rezeption hoffen konnten.

Auch die Übersetzungen der kirgisischen Nationalliteratur sind ein treffendes Beispiel für diese Übersetzungspolitik: Semen Lipkin, jüdischer russischsprachiger Dichter, der seine Lyrik in sowjetischer Zeit kaum publizieren konnte, spezialisierte sich als Übersetzer zentralasiatischer Epik. Von dem kirgisischen Nationalepos Manas, zu dem er auch forschte, fertigte er mehrere Übersetzungsversionen, darunter eine populär nacherzählte an. ${ }^{15}$ Čingiz Ajtmatov, der sich seinerseits in praktisch allen Texten auf das kirgisische Nationalepos bezieht, übersetzte das Epos selbst nicht und auch kein anderer kirgisischer Autor. ${ }^{16}$ Ajtmatov begann seine Karriere als kirgisischsprachiger

12 Vgl. Efim G. Ėtkind: O poetičeskoi vernosti, in: Givi R. Gačečiladze u. a. (Hrsg.): Masterstvo perevoda 1962, Moskau 1963, 97-150, hier: 133, und Harriet Murav: Music from a Speeding Train. Jewish Literature in Post-Revolution Russia, Standford 2011, 301.

13 Vgl. dazu Susanna Witt: Between the Lines. Totalitarianism and Translation in the USSR, in: Brian Baer (Hrsg.): Contexts, Subtexts, and Pretexts. Literary Translation in Eastern Europe and Russia, Amsterdam 2011, 149-70.

14 Vgl. dazu Murav: Music from a Speeding Train (Anm. 12).

15 Manas, übers. von Semjon Lipkin und Mark Tarlovskij, Moskau 1941, ist eine Übersetzung mit Vollständigkeitsanspruch. Manas Velikodušnyj, das in Moskau zuerst 1948 erschien, ist eine populäre Nachdichtung, die später mehrfach wiederaufgelegt wurde, auch postsowjetisch (Riga 1995). Diese Nachdichtung in der zweiten Auflage (Moskau 1958) liegt auch der von Hans Baltzer farbig illustrierten Ausgabe des Verlags Volk und Welt zugrunde, die 1974 in Ostberlin unter dem Titel Manas der Hochherzige. Kirgisisches Heldenepos erschien. Der Autoren- und Übersetzerverweis liest sich dort so: „Nacherzählt von Semjon Lipkin. Die Prosa übersetzte Leo Hornung. Die Nachdichtungen schuf Erich Millstatt. Mit einem Essay des Nachdichters“.

16 Neben Semen Lipkin hat sich der Dichter Vjačeslav Šapovalov als Übersetzer aus dem Kirgisischen einen Namen gemacht. Im Unterschied zu Lipkin und den meisten anderen ist der in Frunze (= Biškek) geborene und lebende Šapovalov ( ${ }^{\star} 1947$ ) als Philologe Spezialist für Turksprachen und hat große Teile des kirgisischen nationalen Corpus ins Russische übersetzt. Zu einer Werkausgabe Šapovalovs haben Lipkin und Ajtmatov gemeinsam ein Vorwort verfasst: Čingiz Ajtmatov, Semen Lipkin: Poėzija v čelovečeskom prostranstve, in: Vjačeslav Šapovalov: Izbrannoye, Bd. 1: V azijskom kruge. Lirika. Poėmy, Biškek 2003. 
Autor, wechselte aber in den 1970er Jahren zum Russisch. Berühmt wurde er mit einem laut Publikationsangabe ins Russische übersetzten Text, auf den ich im Folgenden eingehen werde.

\section{Vorgeschichte: Anfänge der kirgisischen Literatur und ihre sowjetische Modellierung}

Ajtmatov betrat die literarische Bühne des sowjetischen Zentrums mit Beginn des sogenannten ,Tauwetters'. Sein Auftritt und die rasch erfolgende kanonisierende Rezeption seiner ersten Werke markieren zugleich einen zweiten Anfang der kirgisischen Literatur. Im Zuge des sowjetischen Nation-building zu dessen wichtigsten Instrumenten das Schmieden von Nationalliteraturen gehörte, war es in den Jahren des Stalinismus zunächst um die Kanonisierung des Heldenepos Manas durch Verschriftlichung ${ }^{17}$ und Übersetzung ins Russische gegangen. Daneben wurden wie auch in allen anderen als nationale definierten Regionen Versuche der Schaffung einer neuen sowjetischen Literatur unternommen, die jedoch zunächst nicht allzu erfolgreich verliefen.

Noch Anfang des 20. Jahrhunderts war ,Kirgise“ in Zentralasien ein Schimpfwort für verarmte Menschen, Tagelöhner. ${ }^{18}$ Als Ethnonym ist ,Kirgise‘ erst nach 1920 nachgewiesen - davor ordnete man diese nomadisierende, Vieh züchtende Bevölkerungsgruppe in der an die Steppe angrenzenden Bergregion den, Nogaj'-Tataren zu. Obwohl es erste Bestrebungen zur Kodifizierung einer Schriftsprache und Schaffung einer kirgisischen Literatur bereits in vorrevolutionärer Zeit Anfang des 20. Jahrhunderts gegeben hatte $^{19}$ - z. B. Kasym Tynystanov der auf der Basis der arabischen Schrift das erste kirgisische Alphabet schuf und auch die erste kommunistische Zeitung Erkin Too in Kyrgyzstan herausgab, oder Osmonaaly Sydykov's Kurzer Überblick über die kirgisische Geschichte (erschienen 1913 in der baschkirischen Hauptstadt Ufa, südwestlich des Urals und viele tausend Kilometer von Kyrgystan entfernt) ${ }^{20}$ wurde die Alphabetisierung des Landes und die Implementierung einer Literatur im

17 Zuvor wurde das die Gründungsgeschichte des islamisierten turksprachlichen Volks der Kirgisen erzählende Epos, in dem es um die Abwehr gegen die nichtmuslimischen südöstlichen Nachbarn, die Chinesen, Mandschu und Kalmyken geht, mündlich, durch sogenannte Manasči überliefert. Die wissenschaftliche Erforschung und Verschriftlichung begann mit den Arbeiten Wilhelm Radloffs gegen Ende des 19. Jahrhunderts.

18 Obwohl schon Čokan Valichanov, ein kasachischer Gelehrter des 19. Jahrhunderts, die Kirgisen von den Kasachen unterschieden hatte.

19 Vgl. Gulzat Egemberdieva: Can the Subaltern Read? From Literacy to Kyrgyz Literature, Manuskript 2019, die sich auf Osmonaaly Sydykov (1875-1942), Sydyk Karachev (1900-1937), und Kasym Tynystanov (1901-1938) bezieht.

20 Vgl. Osmonaaly Sydykov: Muchtasar tarych Kyrgyzija, Ufa 1913. 
europäisch-modernen Sinn mithilfe von Übersetzungen aus dem Russischen erst im Rahmen des sowjetischen Projekts realisiert. Ein typischer Fall in diesem Zusammenhang ist z. B. Sydyk Karačev, der Puškins Postmeister Erzählungen und den prototypisch sozrealistischen Roman von Ostrovskij Wie der Stahl gehärtet wurde ins Kirgisische übersetzte und dadurch Voraussetzungen auch für sein eigenes literarisches Schaffen (Erzählungen ${ }^{21}$ ) in kirgisischer Sprache schuf. Karačev und Tynystanov fielen den Stalinistischen Säuberungen zum Opfer. Sydykov floh noch vor der Revolution (1916) nach China.

Als Kirgisien 1926 Autonome Sowjetrepublik wurde, ${ }^{22}$ zog dies sämtliche kulturpolitische Maßnahmen des sowjetischen Nation-building bzw. der damals sogenannten ,korenizacija‘, der ,Einwurzelung‘, nach sich: die Kodifizierung der Sprache, flächendeckende Alphabetisierung und Schulbildung; die Sammlung und Erweiterung der modernen Literatur; die Eröffnung von höheren Bildungseinrichtungen wie einer Pädagogischen Hochschule (1932), eines regionalen Sitzes der Akademie der Wissenschaften, einer Staatlichen Bibliothek etc., des Weiteren von Publikationsorganen wie Verlagen und Zeitschriften sowie von Kulturstätten wie einer Oper, eines Theaters, einer Philharmonie und eines staatlichen Museums. Die ersten Akteure dieser Kombination aus Bildungskampagne und Nation-building wurden aus den kirgisischen Dörfern zum Studium nach Taschkent geschickt und, wenn sie von dort zurückkehrten, sofort mit verantwortungsvollen Aufgaben betraut. Aaly Tokombaev, der zweite Literaturgründer Kasymaly Bajalinov und der Vater von Čingiz Ajtmatov, Törökul ${ }^{23}$ waren drei von ihnen. Zurück aus Taschkent wurde Tokombaev sofort Chefredakteur der Zeitung Rotes Kirgistan, Törökul Ajmatov übernahm Parteiämter. Dann wurden beide nach Moskau geschickt, wo Tokombaev Verlagsredakteur von Centrizdat wurde, um dann später zum Leiter des Kirgisischen Staatsverlags und 1934 zum Vorsitzenden des kirgisischen Schriftstellerverbands aufzusteigen, als der er dann als Repräsentant von Kirgisien eine Rede beim 1. Allunionskongress der Sowjetschriftsteller 1934 hielt. Törökul Ajtmatov studierte in Moskau an der Kommunistischen Hochschule der Arbeiter des Ostens und kehrte dann zunächst auch nach Kirgisien zurück, wo er 1926 bis

21 Diesen erhielten Titel wie Der Heirat entkommen oder Die getäuschte Schöne. Vgl. Egemberdieva: Can the Subaltern Read? (Anm. 19), 19.

22 Nachdem die politische Elite bis 1924 die Einheit von Kirgisen und Kasachen behauptet hatte. Vgl. z. B. Zeitung in kirgis-kasachischer Sprache (Almaty). Vgl. Moritz Florin: Kirgistan und die sowjetische Moderne. 1941-1991, Göttingen 2015.

23 Ajtmatovs Vater Törökul ( $\left.{ }^{\star} 1903\right)$, gebürtig aus dem Dorf Šeker wie auch Ajtmatov selbst, war eines von fünf Kindern eines innovationsbegabten Technikers: sein Vater Ajtmat wurde im Dorf ,mašinist" genannt, weil er als erster eine Nähmaschine angeschleppt hatte und für das ganze Dorf darauf nähte. Dann gab er sie an seine Schwestern ab und konstruierte mit einem Freund eine Mühle, die aber nach einem Jahr abbrannte. Danach arbeitete er beim Bau der Turkestan-Sibirischen Eisenbahn - dort lernte Törökul russisch, aber als sein Vater 1920 vor Fertigstellung der Bahn verstarb, kehrte Törökul zunächst in sein Heimatdorf zurück. 
1935 eine steile Parteikarriere in verschiedenen Städten als Parteivorsitzender und verschiedentlich auch als Stadtoberhaupt hinlegte und 1929 das Amt des Kommissars für das Handelswesen der Kirgisischen SSR übernahm. ${ }^{24}$ 1935, da ist sein Sohn Chingiz sieben Jahre alt, wird er neuerlich nach Moskau entsandt: jetzt an die höchst elitäre Kaderschmiede, die Parteihochschule der Roten Professur.

Aber dann ergeht es Törökul Ajtmatov wie vielen aus der ersten sowjetischen Gründergeneration der sowjetischen Nationen: er fällt dem stalinistischen Terror zum Opfer. 1937 wird Törökul verhaftet und 1938 erschossen. Von seinem Tod erfuhr die Familie, die er vor seiner Verhaftung zurück in die Heimat geschickt hatte, erst 1958. 1981 wurde der Vater zusammen mit 137 anderen Erschossenen gefunden und bestattet und ein Denkmal für die Terroropfer errichtet. Ajtmatov ist heute nach seinem Wunsch neben seinem Vater begraben.

Obwohl Aaly Tokombaev und Kasymaly Bajalinov den stalinistischen Terror überlebten - vermutlich, weil sie Weggefährten denunzierten ${ }^{25}$ - waren sie allenfalls institutionell für die transnationale, sowjetische Etablierung der kirgisischen Literatur von Bedeutung. Keiner von ihnen schaffte es in den russischsprachigen sowjetischen Kanon. Auf der Suche nach Vorbildern für einen effektiven Weg, die kirgisische Literatur als moderne sowjetische Nationalliteratur zu etablieren und dadurch transregionale literarische Anerkennung zu erlangen, boten die kirgisischen Vorläufer kein Vorbild. Čingiz Ajtmatov musste sich an Beispielen aus anderen Nationalliteraturen orientieren.

Aber nach den Jugendjahren während des Krieges auf dem kirgisischen Dorf hatte er als Sohn eines ,Repressierten‘ zunächst den Bildungsumweg über ein Studium als Landwirtschaftstechniker in Kirgisien einzuschlagen. Erst im Alter von 28 Jahren wurde er 1956 nach Moskau entsandt und konnte dort ein zweijähriges Externenstudium (die sogenannten ,höheren Kurse') an dem nach Gor'kij benannten Literaturinstitut - der sowjetischen Autorenschmiede und Herz des sowjetischen Literaturprojekts - absolvieren. Im Jahr des XX. Parteitags, auf dem Nikita Chruščev (partiell) die Verbrechen Stalins zur Sprache gebracht und dem Führerkult eine Absage erteilt hatte, kam Ajtmatov damit in eine hauptstädtische Atmosphäre einer fast explosionsartigen Weltöffnung. 1956 fand in Moskau eine große Picasso-Ausstellung statt, auf der die meisten jüngeren sowjetischen Besucher erstmals kubistische Kunstwerke zu Gesicht bekamen. 1957 wurde Ajtmatov dann Zeuge der 6. Weltfestspiele der Jugend und der Studenten, dem größten derartigen Festival, ${ }^{26}$ das es bis dahin gegeben hatte, mit

24 Zur Törökul Ajtmatovs Karriere im historischen Kontext vgl. Florin: Kirgistan (Anm. 22), 36 ff.

25 Vgl. ebd., 39.

26 Seit 1947 wurden vom Weltbund der Demokratischen Jugend alle zwei Jahre solche Festspiele in den Hauptstädten des sich formierenden sogenannten Ostblocks bzw. der Sowjetunion nahestehender Länder ausgerichtet. Vor Moskau waren die Austragungsorte Prag, Budapest, Ostberlin, Bukarest und Warschau. 1959 und 1962 fanden die Weltjugendspiele in den Hauptstädten der ,neutralen Staaten Österreich und Finnland statt. Zur Geschichte der Weltjugendspiele vgl. Klemens Vogel: Die 
34000 Teilnehmer:innen aus 131 Ländern, in dessen Rahmen eine große Ausstellung zeitgenössischer Kunst aus westlichen Ländern und Sowjetunion gezeigt wurde, auf welcher alle Stilrichtungen der Moderne zu besichtigen waren, auch solche, die seit zwei Jahrzehnten in der Sowjetunion als ,bourgeois‘ und ,formalistisch'verunglimpft worden waren, wie abstrakte Kunst und Expressionismus. 1957 wurde auch das 1. International Geophysical Year ${ }^{27}$ ausgerufen, das den Beginn einer kontinuierlichen blockübergreifenden Wissenschaftskooperation, den internationalen Datenaustausch, aber auch den Anfang der internationalen wissenschaftlichen Bestrebungen für Umweltschutz markierte und den Abschluss des internationalen Vertrages zur Erforschung, zum Schutz und zur friedlichen Nutzung der Antarktis vorbereitete. Umgekehrt wurde in diesen Jahren auch die junge sowjetische Kunst, die nun entstand, mit großem Interesse und Begeisterung im Westen aufgenommen. So wurde z. B. Michail Kalatozovs Film Wenn die Kraniche ziehen 1958 als erster sowjetischer Film in Cannes mit der Goldenen Palme ausgezeichnet: Ein Film, dessen unerschrockener Individualismus, dessen Mut zu komplexen und widersprüchlichen Charakteren und dessen lyrische Emotionalität in ganz klarer ästhetischer Nachbarschaft zu Ajtmatovs Erfolgsnovelle stehen.

\section{Ajtmatov - Student des Gor'kij-Instituts: Moskau 1956-1958}

Als Ajtmatov 1956 sein Studium als Externer am Gor'kij-Institut aufnahm, studierten dort auch schon etwas jüngere Zeitgenossen wie Evgenij Evtušenko und die tatarischstämmige Moskauer Dichterin Bela Achmadulina und der tschuwaschische Dichter Gennadij Ajgi. Sie alle standen in einem positiven Verhältnis zu Boris Pasternak und wurden - im Zusammenhang der Nobelpreisverleihung an Pasternak 1958 - vom Studium ausgeschlossen. Ajgi, der auf Empfehlung Pasternaks zum Russischen als erste Schreibsprache wechselte, bekam Schwierigkeiten mit seinen Gedichten, die dem sozialistischen Realismus nicht entsprachen, und durfte nur den Studiengang für Übersetzer abschließen. Bis 1991 wurde kein einziges seiner russischsprachigen Gedichte offiziell publiziert, während er bereits seit den 1970er Jahren im westlichen Ausland als Exot eines global anerkannten Modernismus Berühmtheit erlangt hatte und in den 1980ern für den Nobelpreis vorgeschlagen wurde. ${ }^{28}$ Ajtmatov konnte als

Weltfestspiele damals und heute (2003). Online abgerufen am 17.04.2021 auf Bundeszentrale für politische Bildung, unter: http://www.bpb.de/geschichte/deutsche-geschichte/weltfestspiele-73/65342/ die-weltfestspieledamals-und-heute.

27 Vgl. Marcel Nicolet: The International Geophysical Year 1957-1958. Great Achievements and Minor Obstacles, in: GeoJournal 4 (1984), 303-320.

281971 erschien ein erstes Bändchen mit Ajgis Gedichten in der edition suhrkamp. Karl Dedecius, der sie übersetzt hatte, schrieb dazu ein gewichtiges Nachwort. Zu Ajgi vgl. Karl Dedecius: Nachwort, in: 
Externer das Gor'kij-Institut passieren. Nach eigener Aussage lernte er in diesen ungeheuer dynamischen Jahren 1956-1958, die er in Moskau erlebte, nicht besonders viele Kolleginnen und Kollegen kennen.

Aber auch er beschritt in der Literatur ganz neue Wege. Dafür, wie sehr sich das spätere Studium und die Jahre in der in internationaler Kommunikation erblühenden Hauptstadt für Ajtmatov lohnten und wieviel Inspiration ihm diese Atmosphäre gab, ist Ajtmatovs Abschlussarbeit am Gor'kij-Institut, mit der er zuerst einen sowjetischen und dann auch einen Welterfolg landete, das beste Zeugnis. Die Erzählung Džamilja wurde 1958 nicht etwa in der für multinationale Sowjetliteratur bestimmten Zeitschrift Družba narodov (dt. Völkerfreundschaft) gedruckt, sondern in Novyj mir (dt. Neue Welt), jener Zeitschrift, die unter dem Chefredakteur Aleksandr Tvardovskij das literarische Gesicht der Epoche des Tauwetters maßgeblich geprägt hat. ${ }^{29}$ Charakteristisch für diese neuen literarischen Tendenzen waren andere Perspektiven auf den Krieg, die der stalinistischen Heroisierung entgegenstanden (z. B. in der sogenannten Leutnantsprosa mit ihrer Schützengrabenperspektive), die Autoren wie Viktor Nekrasov $^{30}$ oder Vasilij Grossman in einer auf ,Aufrichtigkeit ${ }^{631}$ abzielenden Erzählhaltung ${ }^{32}$ entwickelten, die Thematisierung bislang tabuisierter Themen wie z. B. Gulag ${ }^{33}$, eine Tendenz zu größerer psychologischer Komplexität und Individualität in der Charakterzeichnung und ein allgemeiner lyrischer Trend in der Literatur, dessen Anfänge auf die Dichtung der Jahre des Kriegsendes zurückgingen (z. B. Konstantin Simonov). Ajtmatovs Debut trifft den Zeitgeist des Tauwetters genau, und es gelingt ihm, den multinationalen Akzent im Zentrum des Interesses dieser Jahre zu platzieren.

Džamilja ist in der Erstpublikation als Übersetzung ausgewiesen. ${ }^{34}$ Obwohl Ajtmatov bilingual aufgewachsen war, schrieb er damals noch zuerst auf Kirgisisch.

Gennadij Ajgi. Beginn der Lichtung, Frankfurt a. M. 1971. 1972 erhielt Gennadij Ajgi den Lyrik-Preis der Académie Française. Später folgten zahlreiche internationale Auszeichnungen wie z. B. der PetrarcaPreis 1993 und der Boris Pasternak Preis 2000. Zu Ajgi im Kontext der multinationalen Sowjetliteratur vgl. Susi K. Frank: Multinational Soviet Literature. The Project and Its Post-Soviet Legacy in Iurii Rytkheu and Gennadii Aigi, in: Klavdia Smola, Dirk Uffelmann (Hrsg.): Postcolonial Slavic Literatures after Communism, München 2016, 191-218.

29 Vgl. Marietta Čudakova: Proza Ottepeli, in: Ottepel'. Gosudarstvennaja Tret’jakovskaja galereja, Moskau 2017, 56-105.

30 Nekrasovs erster Kurzroman V rodnom gorode (In der Heimatstadt) erschien 1954 in Novyj mir, 10/11. $31 \mathrm{Vgl}$. den programmatischen epochemachenden Artikel von Igor' Pomerancev: Ob iskrennosti v literature [Über Aufrichtigkeit in der Literatur], in: Novyj mir 12 (1953), 218-245.

32 Vasilij Grossmans Za pravoe delo, der erste Teil seines Romans Leben und Schicksal erschien bereits 1952 in Novyj mir. Zum Ansturm der Leser:innen auf diese Publikation vgl. Semen Lipkin: Žizn' i sud'ba Vasilija Grossmana, Moskau 1990, 138.

33 Zuerst durch den Roman von Vladimir Dudincev Ne chlebom edinym (Nicht von Brot allein), erschienen zuerst 1956 in Novyj mir.

34 Čingiz Ajtmaov: Džamilja. Povest’. Perevela s kirkizskogo A. Dmitrieva. In: Novyj mir 8 (1958), 3-31. 
Es ist schwer nachzuweisen, ob Ajtmatov seinen Text selbst übersetzt hat. Die Angabe in der Publikation suggeriert jedenfalls, dass Anna Dmitrieva (eigentl. Anna Dmitrievna Mel'man, 1916-1984), die danach auch für die meisten seiner anderen Texte aus den 1960er Jahren als Übersetzerin angegeben wird, einen wichtigen Anteil daran hatte. Ajtmatov hat später in Dankbarkeit auf sie als strenge Kritikerin und Stilistin verwiesen. Die Tatsache dieser Erstpublikation in Übersetzung ist jedenfalls in doppelter Hinsicht symptomatisch für die sowjetische Situation: Erstens zeigt sie, dass es kein Problem darstellte, nicht mit einem Originaltext, sondern mit einer Übersetzung berühmt zu werden. Auch der internationalen Rezeption schadete das offensichtlich nicht. Zum anderen war diese Publikation nach Ajtmatovs Aussage auch der literaturpolitischen Taktik von Aleksandr Tvardovskij geschuldet. Tvardovskij, so berichtet Ajtmatov in seiner Autobiographie, hatte vorhergesehen, was wenig später tatsächlich eintraf: dass die kirgisische Rezeption der Erzählung wegen der mehrfachen Tabubrüche in der Gestaltung der Protagonistin und ihres Handelns ziemlich kritisch verlaufen würde; er hatte Ajtmatov deshalb zu einer Vorpublikation in der Moskauer Zeitschrift des Sowjetischen Schriftstellerverbands geraten, die ihm gegenüber den kirgisischen Kritikern Autorität verschaffen würde. ${ }^{35}$ Im Einklang mit dieser Publikationssituation, aber auch entsprechend der Tatsache, dass Literaturübersetzungen im sowjetischen Kontext vollkommen unproblematisch und praktisch Originalen entsprechend gehandhabt wurden, entstanden auch sämtliche späteren Übersetzungen der Erzählung aus dem Russischen, die erste schon ein Jahr später ins Französische. Später folgten Übersetzungen in weitere 24 Sprachen. Wie lässt sich dieser Erfolg erklären?

\section{Džamilja}

Was für ein Text ist nun Džamilja, mit dem Ajtmatov zugleich die poststalinistische sowjetisch-kirgisische Literatur neu begründete und in den Kanon der Weltliteratur einging? Wie konnte er, der aus der hintersten sowjetischen Peripherie kam und in der Sowjetunion einen literaturpolitischen Auftrag zu erfüllen hatte, sich mit ein und demselben Text auch jenseits der sowjetischen Einflusszone im internationalen Literaturraum soviel Gehör verschaffen?

Kurz zum Inhalt und zur Erzählstrategie: Ajmatovs Erzählung ist zugleich die Coming of age-Geschichte eines jungen Künstlers und die Geschichte einer die gesellschaftlichen Konventionen und Erwartungen der kirgisischen Dorfgemeinschaft sprengenden Liebe in Zeiten des ,Großen Vaterländischen Krieges‘, deren Sujet, deren

35 Vgl. Čingiz Ajtmatov: Detstvo. Avtobiografičeskie vospominanija, Biškek 2011, 94-97. Die erste Publikation in kirgisischer Originalsprache erschien aber doch noch im selben Jahr: Čingiz Ajtmatov: Obon [Melodie], Frunze: Kyrgyz Basmasy, 1958. 
individualisierende Figurenzeichnung und deren lyrische Stimmlage als geradezu paradigmatisch für die Geburtsstunde des sogenannten ,Tauwetters' gelten können. ${ }^{36}$ Aus der vom Erzähler erinnerten Perspektive des heranwachsenden Jungen, der er einmal war, ${ }^{37}$ wird die Geschichte der Liebe einer verheirateten jungen Frau, deren Mann im Krieg ist, zu einem verwundet heimgekehrten Sonderling erzählt, mit dem sie schließlich das Dorf verlässt. Der Junge, der dies beobachtet, ist Held der zweiten, rahmenden Erzählung, die (mit)gefühlte Liebe inspiriert in ihm den Künstler, zu dem er nachfolgend wird. Wie die Ekphrasis des von ihm aus der Erinnerung gemalten Bildes am Anfang der Erzählung andeutet, hat der Erzähler-Protagonist das Dorf ebenfalls verlassen und wurde im fernen Zentrum des Landes Maler:

Wieder einmal stehe ich vor dem kleinen Bild mit dem schlichten, schmalen Rahmen. Morgen in aller Frühe muß ich in den Aul (Dorf) fahren, und ich betrachte das Bild lange und aufmerksam, als könnte es mir gute Wünsche auf den Weg mitgeben. Ich habe dieses Bild noch nie auf eine Ausstellung geschickt, und wenn meine Verwandten aus dem Aul mich besuchen kommen, verstecke ich es sogar. Nicht daß ich mich seiner zu schämen brauchte, aber es ist alles andere denn ein Kunstwerk. Es ist ganz schlicht, so schlicht wie die Landschaft, die ich darauf dargestellt habe. Im Hintergrund sieht man den Rand des fahlen Herbsthimmels und scheckige, vom Wind gejagte Wolken über einer fernen Bergkette, im Vordergrund Wermutsträucher in der rötlichbraunen Steppe und einen Weg, fast schwarz, noch naß vom Regen, am Wegrain stehen dicht gedrängt Büschel von dürrem, geknicktem Pfriemengras. Der ausgewaschenen Fahrinne entlang ziehen sich die Spuren zweier Fußgänger hin. Je weiter sich die Spuren entfernen, um so undeutlicher werden sie, und die beiden Wanderer selbst scheinen beim nächsten Schritt hinter dem Rahmen zu verschwinden. Der eine von ihnen ... Aber ich will nicht vorauseilen. ${ }^{38}$

36 Vgl. Gulzat Egemberdieva: Silent Voices. Kyrgyz Women and „the Great Patriotic War“ in Chingiz Aitmatov's early work, in: Kumi Tateoka, Valerij Gretchko, Yuika Kitamura (Hrsg.): Found in Translation. Transformation, Adaptation and Cross-Cultural Transfer, Belgrad/Kobe 2016, 122-128. Egemberdieva schreibt: „The novella violates two taboos at the same time: that of traditional Kyrgyz society, where a wife is forever the property of her husband and his family, and Soviet morality. Jamila betrays a husband who is a hero of the Great Patriotic War for a man whose demobilization had good chances of being interpreted as an escape from the war. There is no doubt that the novella is the product of the Thaw." Ebd., 125.

37 Zum Verfahren der erinnerten Kinderperspektive vgl. Mechthild Barth: Mit den Augen des Kindes. Narrative Inszenierungen des kindlichen Blicks im 20. Jahrhundert, Heidelberg 2009; Olga Bazileviča: Als das Ich Kind war. Literatur, Kindheit und historisches Erinnern in Deutschland, Russland und Lettland, Würzburg 2020.

38 Tschingis Aitmatow: Dzhamilja. Erzählung, mit einem Vorwort von Louis Aragon, übers. von Gisela Drohla, Frankfurt a. M. 1972, 10. Russisch: „Вот опять стою я перед этой небольшой картиной в простенькой рамке. Завтра с утра мне надо ехать в аил, и я смотрю на картину долго и пристально, словно она может дать мне доброе напутствие. Эту картину я еще никогда не выставлял на выставках. Больше того, когда приезжают ко мне из аила родственники, я стараюсь запрятать ее подальше. В ней нет ничего стыдного, но это далеко не образец искусства. Она проста, как проста земля, изображенная на ней. В глубине картины - край осеннего поблекшего неба. Ветер гонит над далекой горной грядой быстрые пегие тучки. На первом плане - красно-бурая полынная степь. И дорога черная, еще не просохшая после 
Dem Geist dieser ersten nachstalinistischen Jahre folgend, greift Ajtmatov in dieser künstlerisch beeindruckenden Miniatur sämtliche von Gor'kij und Stalin postulierten Maximen sowjetischer Weltliteratur auf und transformiert sie zugleich in radikal innovativer Weise. Zweifelsohne basiert dieser Text auf dem Verständnis des ,Schriftstellers als Ingenieur der menschlichen Seelen', sein menschen- und seelenbildendes Anliegen ist offensichtlich, aber ganz und gar nicht in jener martialisch autoritären Weise, wie es für den Sozialistischen Realismus der 1930er und 1940er Jahre typisch gewesen war. Zweifelsohne setzt dieser Text die stalinsche Forderung, ,national in der Form, sozialistisch im Inhalt‘ zu schreiben, um, aber er tut es auf neue Weise, indem ,sozialistisch' nie in Frage gestellt, aber mit ,humanistisch' gleichgesetzt wird, einem klar auf Gor'kij zurückgehenden ideologischen Kodewort, das im Tauwetter und insbesondere im Kontext eines neuen, eine globale Perspektive auf die Menschheit eröffnenden Internationalismus ganz neue Brisanz erhielt. Und zweifelsohne wird hier auch die Devise des Sozialistischen Realismus, „wahrhaftige, historisch-konkrete Darstellung der Wirklichkeit in ihrer revolutionären Entwicklung“39 ${ }^{* 3 m g e s e t z t . ~ A b e r ~ a u c h ~}$ sie in einer spezifischen Weise, bei der Zukunftszugewandtheit und Zukunftshoffnung in der Richtung vom traditionalen Dorf hin zu einer Moderne stark akzentuiert sind, ohne plakativ das Narrativ der ,Bildungsreise، ins Zentrum auszubuchstabieren. Ohne Reflexion führen Handlung und Darstellung vor Augen, dass die Hoffnung auf eine ,lichte Zukunft‘ mit Werten wie Freiheit und verantwortungsvoller Selbstbestimmung starker Individuen verbunden werden und damit Hauptwerten des stalinistischen Sozrealismus wie Selbstaufopferung und bedingungslosem Verzicht widersprechen. Ebenfalls in diametralem Gegensatz zu stalinistischen Narrativen steht die Nichtentgegensetzung von Zukunft und Vergangenheit, von Herkunft und Aufbruch. Durch die komplexe Perspektivierung kann radikale Abgrenzung durch bewahrende Erinnerung ersetzt werden, Erinnerung, die wie ein Heimatmuseum der Vergangenheit als Herkunft Identität stiftende Funktion beimisst, ohne sie deswegen zu perpetuieren. Auch dieses Verfahren kann als geradezu idealtypische - und doch innovative - Umsetzung der Forderung nach einer kritisch-produktiven, schöpferischen ,Aneignung des kulturellen Erbes' gesehen werden, wie es in Zeiten Stalins propagiert wurde. Aber auch diese Devise wird hier ganz neu interpretiert, z. B. auf intertextueller Ebene, wo Ajtmatov sich auf das kirgisische Nationalepos Manas als lebendiges Instrument der Gemeinschaft stiftenden Identifikation bezieht. Mit dieser Strategie, die musealisierende Gedächtnisbildung mit Zukunftszugewandtheit in Einklang bringt, trifft Ajtmatovs Text

недавних дождей. Теснятся у обочины сухие, обломанные кусты чия. Вдоль размытой колеи тянутся следы двух путников. Чем дальше, тем слабее проступают они на дороге, а сами путники, кажется, сделают еще шаг - и уйдут за рамку. Один из них ... Впрочем, я забегаю немного вперед.“ Čingiz Ajtmatov: Džamilja, in: Novyj mir 8 (1958), 3-31, hier: 3.

39 Statuten des Sowjetischen Schriftstellerverbands (Ustav Sojuza Sovetskich Pisatelej SSSR), publiziert im Band Pervyj vsesojuznyj s'ezd (Anm. 2), 712-714. 
ins Herz der sich 1958 abzeichnenden neuen literarischen Entwicklungen und positioniert sich hier auch ganz eigenständig im Kontext, aber in gewisser Opposition zu der damals noch im Entstehen begriffenen und für die sowjetische Literatur der 1960er und 1970er Jahre wichtigen Tendenz der sogenannten Dorfprosa, deren russisch nationaler Tendenz und deren neo-patriarchalem Konservatismus Ajtmatov eine zwischen Archaik und Moderne vermittelnde Position entgegensetzt. ${ }^{40}$

\section{Zur ersten russisch-sowjetische Rezeption von Džamilja 1958}

Im Zusammenhang des ausführlichen Berichts über eine „Dekade der kirgisischen Kunst und Literatur“ in Moskau ${ }^{41}$ veröffentlichte die Literaturnaja gazeta, das Hauptorgan der populären sowjetischen Literaturkritik, am 23.10.1958, dem Tag, an dem die Verleihung des Nobelpreises an Boris Pasternak bekanntgegeben und umgehend von der Sowjetunion verurteilt wurde, eine Rezension zu Džamilja. Nicht ein namhafter russischer Autor hatte sie geschrieben, aber auch nicht irgendein Kritiker, sondern der noch unter Stalin hochdekorierte kasachische Sowjetschriftsteller Muchtar Auėzov (1897-1961). Auėzov war für seinen historisch-biographischen Roman Put’ Abaja (dt. Abajs Weg) ${ }^{42}$ über die Formierung der kasachischen Nation im späten 19. Jahrhundert, in dessen Zentrum der vorrevolutionäre Dichter Abaj Kunanbaev stand, den der Roman als Gründervater der modernen kasachischen Literatur modellierte, ${ }^{43} 1949$ mit dem Stalinpreis ausgezeichnet worden und galt seinerseits als Begründer der sowjetischen kasachischen Nationalliteratur. Mit diesem literaturgenealogischen nationalen Sujet wurde Auėzov der Forderung Stalins (und Gor'kijs) nach nationaler Kanonisierung perfekt gerecht. Wie deutet Auėzov die anscheinend so andere - nämlich mit einem Sujet von viel weniger nationalem Gewicht arbeitende - Erzählung von Ajtmatov?

40 Zur Tendenz der sogenannten ,Dorfprosa“ vgl. jüngst Anna Razuvalova: Pisateli ,derevenščiki“. Literatura i konservatvinaja ideologija 1970-ch godov, Moskau 2015.

41 Solcherart Festivals fanden als eine Art nationale ,Leistungsschau' regelmäßig in der Metropole der Sowjetunion statt.

42 Auėzovs Roman erschien zwischen 1942 und 1956 in vier Bänden (1942 erschien der erste Band auf Kasachisch in Almaty, 1947 der zweite ebenda. 1948 erschienen die beiden ersten Bände in russischer Übersetzung in Moskau. 1954 vollendete Auėzov die Tetralogie. Bis zur vollständigen Publikation derselben dauerte es allerdings noch bis 1957, als sowohl eine kasachische als auch eine russische Ausgabe erschienen). Der erste Band wurde übersetzt von Anna Nikol'skaja: Moskau 1945.

43 Abaj selbst hatte gegen Ende des 19. Jahrhunderts bereits ein nationales Literaturprojekt gehabt, war dabei auch an Russland als Tor zur europäischen Aufklärung orientiert und hatte vieles aus dem Russischen ins Kasachische übersetzt. 
Auėzov sieht in Džamilja das Werk, in dem Ajtmatov seine künstlerische Individualität und Originalität voll entwickelt hat. Für ihn ist der Text zugleich gattungsbegründend im Kontext der mittelasiatischen Literaturen, die bislang nur den Roman kannten und anstrebten. Damit erkennt Auėzov Ajtmatovs Werk als Gegenentwurf an zu dem von ihm selbst gewählten Gattungsformat des großen, mehrbändigen Romans und als eine neue kleine Prosaform: die lyrische Erzählung. Diese Zuordnung ermöglicht es Auėzov zugleich, nicht umfänglich auf den Inhalt einzugehen, sondern vor allem diese lyrische Dimension zu erläutern. Er betont zum einen die Darstellung aus der subjektiven Innenperspektive, dank der das reiche Seelenleben der Figuren insbesondere des jugendlichen Erzählers Seït ${ }^{44}$ - dargestellt werden könne, sowie zum anderen den lyrischen Stil, der vieles ,unausgesprochen' lässt ${ }^{45}$ und dadurch Sehnsucht evoziert. Exemplarisch dafür sieht Auėzov das Lied des Protagonisten Danijar auf welches auch der kirgisische Originaltitel Melodie (Owon) verwies -, das er nicht nur als Symbol der Gleichung von Liebe und künstlerischer Inspiration verstanden wissen möchte, die den semantischen Kern der Erzählung bildet, sondern auch als Metapher der tiefen Seelen der kirgisischen Protagonisten, als ,Seelenmelodie‘.

Mit dieser Deutung, die die regionale Dimension akzentuiert und den Stil geopsychologisch auffasst, ordnet Auėzov Ajtmatovs Erzählung in Hinblick auf ihre literarische und kulturelle Leistung als Äquivalent und - ästhetisch gesehen - als komplementären Gegentext zu seinem eigenen Roman ein: regional Identifikation stiftend und regionales Wissen an ein überregionales Publikum vermittelnd und damit auf transregionale Kanonisierung abzielend. Der Hinweis auf die andeutende Manier, die „Unausgesprochenheit‘ ermöglicht es Auėzov, auf eine Kommentierung der subtilen Auseinandersetzung Ajtmatovs mit politisch durchaus heiklen Motiven zu verzichten und zugleich auf eine auch in Zeiten des Tauwetters noch höchst aktuelle Strategie literarischen Schreibens unter den schwierigen sowjetischen Bedingungen hinzuweisen.

Im selben Jahr, in dem Boris Pasternak mit seinem Roman Doktor Živago der von ihm explizit kritisierten ,Unausgesprochenheit‘ (nedoskazannost) als Merkmal der die Zensur stets mitbedenkenden und sich selbst zensierenden zeitgenössischen Literatur entgegentrat - in Doktor Živago, so Pasternaks Programm, sollte alles präzise beim Namen genannt werden -, veröffentlichte Ajtmatov eine Erzählung, deren Verfahren geradezu als Muster einer Poetik der ,Unausgesprochenheit‘ angesehen werden kann, bei der es aber dennoch auch um ein neues ästhetisches Programm ging. Die Inszenierung des naiven (noch) kindlichen Blicks des Jungen, der der Ich-Erzähler

44 Die Übersetzung von Hartmut Herboth übernimmt die Schreibweise des Namens aus dem russischen Text. In der Übersetzung von Gisela Drohla wird er „Said“ genannt.

45 „За пределами повести лежит много недосказанного, зовущего сердце читателя. Так и должно быть в настоящей лирической повести“ (Hinter dem expliziten Text der Erzählung liegt viel Unausgesprochenes, das das Herz des Lesers berührt. So muss eine echte lyrische Erzählung verfasst sein), heißt es in Auėzovs Rezension in der Literaturnaja Gazeta vom 23.10.1958. 
einmal war, motiviert zum einen die Reduktion auf eine Perspektive der Identität und der Selbstverständlichkeit - des Dorfes wie der Zugehörigkeit zur Sowjetunion, der Vermischung von alten Traditionen und Arbeitspraktiken sowie Resten muslimischen Glaubens mit sowjetischen Strukturen und Ansätzen von Modernisierung -, eine Perspektive, der alles vertraut ist, was da geschieht, wie die Menschen sehen, fühlen und handeln, aber zum anderen auch auf eine Perspektive der Unvoreingenommenheit, aus der das soziale Verhalten der Menschen auf dem Dorf, Ab- und Ausgrenzungen sowie Konventionen und Erwartungen beobachtet werden, aber abweichendes Verhalten nicht voreingenommen verurteilt wird. Das fiktionale Spiel mit der erinnerten Kinderperspektive dient hier nicht einer satirischen Verfremdung und Abgrenzung, sondern der empathischen Erinnerung an eine Situation, in der Neues direkt im und aus dem Alten entstanden ist. So kann die Figurenkonstellation aus drei starken, von der Dorfgemeinschaft nicht voll akzeptierten Individuen, die frei und selbstbestimmt handeln und damit gesellschaftliche Schranken überschreiten, ohne sich um die Meinung des Kollektivs zu kümmern, durchweg positiv konnotiert werden, können heikle Themenkomplexe nebenbei, allusiv angesprochen und dann nicht durch verbale Reflexion, sondern durch das Handeln der Figuren und seine implizite Bewertung durch den Erzähler abgehandelt werden: die kulturelle Differenz zwischen Kirgisen und Kasachen und der Umgang mit im Krieg Verwundeten oder in Gefangenschaft Geratenen im Gegensatz zu ruhmreich Heimgekehrten. ${ }^{46}$ Und so können zugleich Lehren erteilt werden, die eine Gegenüberstellung von unaufgeklärter Dorfgemeinschaft und Moderne implizieren - wie das als emanzipatorisch zu wertende Handeln der Protagonistin $^{47}$-, ohne diese Opposition und die Entscheidung für die Moderne plakativ explizit machen zu müssen. Derselben äsopischen Strategie ist auch die Ekphrasis des Bildes, das der Erzähler gemalt hat, am Anfang und dann wieder am Ende der Erzählung zuzuordnen. Sie, die Ekphrasis, markiert dreierlei: die naive Idealisierung der Geborgenheitssituation der Kindheit (das Bild als Realisierung der ,Idylle`), die absolute Vergangenheit des Erinnerten (was im Sinne des sowjetischen Aufbruchs gedeutet werden kann), und die Bewahrung des Angedenkens an die Herkunft im Gedächtnis mithilfe der Kunst. Letzteres ist für Ajtmatovs Poetik, für sein gesamtes

46 Aus der Perspektive des kirgisischen Dorfes haftet Danijar der Makel der Entwurzelung und des Grenzgängertums nach Kasachstan an. Er selbst - und der Erzähler Seït - haben damit kein Problem, Kasachen und Kirgisen gehören eng zusammen, was im Sinne einer sowjetischen Kritik am engstirnigen Nationalismus gedeutet werden kann. Kritischer ist das Motiv des verwundeten (oder in Gefangenschaft geratenen) Kriegsheimkehrers in Relation zum erfolgreichen Kriegshelden: Džamilja entscheidet sich aus tiefem Gefühl für den ,unehrenhaften“ Heimkehrer und dieser, und nicht der Kriegsheld, steht im Zentrum der Handlung.

47 Ajtmatov hatte den Plot der Liebesgeschichte in einer Erzählung seines Landsmanns Kasymaly Bajalinov von 1947, Na beregach Issyk-Kulja (An den Ufern des Issyk-Kul) gefunden, und wertete deren Figurenkonstellation um: Während Bajalinov das Verhalten einer jungen Frau im Kolchos, deren Mann im Krieg war, als Untreue verurteilt hatte, suchte Ajtmatov eine andere Interpretation. 
literarisches Programm, wie er es auch in allen späteren Erzählungen und Romanen verfolgt hat, der wohl wichtigste Aspekt: Erinnerung als stärkste Kraft und Bedingung einer positiven Zukunft.

\section{Die Anfänge der Rezeption in Ost- und Westdeutschland}

Den Weg nach Deutschland, auch nach Ostdeutschland, bahnte Džamilja aber nicht die sowjetische Aufnahme, sondern ein internationaler Zwischenschritt über Frankreich: Louis Aragon, seit den 1930er Jahren aktives Mitglied der sozialistischen Internationale und seit dem Schriftstellerkongress 1934 aufs Engste dem sowjetischen multinationalen Weltliteraturprojekt verbunden, lernte Ajtmatovs Erzählung über Auėzov kennen, für den er sich bereits zuvor engagiert hatte. Wie zuvor Auèzovs Roman übersetzte Aragon Ajtmatovs Erzählung und ließ sie schon 1959 ebenfalls bei Gallimard publizieren. Es war der Titel des von Aragon hinzugefügten Vorworts, der wesentlich zum Welterfolg beitrug: Die schönste Liebesgeschichte der Welt. Ich komme weiter unten darauf zurück.

Mit dem Erscheinen der als Djamila von Hartmut Herboth für die ,bunte Reihe‘ des Verlags Kultur und Fortschritt übersetzten Erzählung begann 1960 Čingiz Ajtmatovs deutsche Rezeption, die sich bis zum Ende der 1980er Jahre durchgängig als doppelte entwickelte. ${ }^{48}$ Das begann schon 1962 mit einer Konkurrenzübersetzung - betitelt Dzhamilja - im Insel-Verlag.

48 Vgl. Tschingis Aitmatow: Djamila. Novelle, übers. von Hartmut Herboth, Berlin 1960; und in Oppositon dazu: Tschingis Aitmatow: Dshamilja. Erzählung, mit einem Vorwort von Louis Aragon, übers. von Gisela Drohla, Frankfurt a. M. 1972. Bis hin zu Ajtmatovs letztem Roman Placha (Richtstatt) wurden praktisch alle seine Texte parallel in verschiedenen Übersetzungen und unter unterschiedlichen Titeln in Ost- und Westdeutschland publiziert, letzteres auch sogar dann, wenn es sich um dieselbe Übersetzung handelte, die in Lizenz genutzt wurde. Vgl. z. B. Tschingis Aitmatow: Ein Tag länger als ein Leben. Roman, übers. von Charlotte Kossuth, München 1981; und in Opposition dazu: Ders.: Der Tag zieht den Jahrhundertweg, übers. von Charlotte Kossuth, Ostberlin 1982; oder: Ders.: Der Richtplatz, übers. von Friedrich Hitzer, Zürich 1987; und dagegen: Ders.: Die Richtstatt, übers. von Charlotte Kossuth, Ostberlin 1987. Zur deutsch-deutschen Übersetzungsgeschichte in der Nachkriegszeit vgl. den Überblick von Friedrich Hübner: Russische Literatur des 20. Jahrhunderts in deutschen Übersetzungen, Köln 2012. Was für die Publikationsgeschichte zutrifft, stimmt ein Stück weit auch für die Forschungsrezeption, wobei hier die ostdeutsche Seite überwiegt: Vgl. Irmtraud Gutschke: Menschheitsfragen, Märchen, Mythen. Zum Schaffen Tschingis Aitmatows, Halle (Saale)/Leipzig 1986; und: Irmtraud Gutschke: Das Versprechen der Kraniche. Reisen in Aitmatows Welt, Halle (Saale) 2018. Oder die ausführliche Darstellung bei Willi Beitz (Hrsg.): Vom Tauwetter zur Perestrojka. Russische Literatur zwischen den Fünfziger und den Neunziger Jahren (zu Tschinigs Aitmatov, 245-252), Berlin/ Frankfurt/Wien 1994, die der einzigen westdeutschen - und auch bereits postsowjetischen Buch- 
Aufgrund der Archivlage ${ }^{49}$ beschränke ich mich hier zunächst auf die westdeutsche Publikationsgeschichte. Sie zeigt erstens, dass Aragons Vorwort hier eine wichtige Promotionsfunktion hatte, zweitens, was für ein verlegerisch umkämpftes Objekt russisch-sowjetische Literatur um 1960 auch im Westen war, drittens, dass die Verlegung russischer-sowjetischer Bücher (das gilt für Bücher aus dem sogenannten Ostblock allgemein) weniger durch ein eigenes, westliches (Welt)Literaturprogramm bestimmt war, als durch Reaktion auf sowjetische (Verlags-)Politik, und viertens, dass Publikationen ziemlich stark von der Initiative einzelner Lektor:innen und Übersetzer:innen abhingen.

Die Geschichte der Übersetzerin von Džamilja, Gisela Drohla, in deren Übersetzung die Erzählung 1962 im Insel-Verlag erschien, liest sich teilweise wie ein Verlagskrimi. Gisela Drohla, Slavistin, Byzantinistin und schließlich auch Kartvelistin (in den 1970er Jahren arbeitete sie an einer Dissertation über georgische Literatur), war von 1959 bis 1965 als externe Lektorin, Übersetzerin und Redakteurin im Insel-Verlag tätig und mit der Konzeption des russischen Programms sowie Editionen und Übertragungen russischer Werke betraut. Im Anschluss arbeitete sie noch bis in die 1970er Jahre in derselben Funktion bei Suhrkamp. Im Insel-Verlag verband Drohla ein enges produktives Verhältnis mit Fritz Arnold, dem Leiter des Verlags, woraus zunächst die Anthologie Russische Lyrik des XX. Jahrhunderts (1959) entstand, die in bereits vorhandenen Übertragungen die wichtigsten Autoren des russischen ,Silbernen Zeitalters“ vorstellte: Fëdor Sologub, Aleksandr Blok, Sergej Esenin, Vladimir Majakovskij, Boris Pasternak, Osip Mandel'štam.

Dass die Publikation russischer Literatur der Moderne Ende der 1950er Jahre ein verlegerisch heißes Thema war, zeigen die darauffolgenden Übersetzungen Drohlas, die alle in hektischer Konkurrenz mit anderen Verlagen entstanden: zunächst die erste deutsche Publikation von Andrej Belyjs Jahrhundertroman Peterburg - Drohla übersetzte ihn in nur zwei Monaten, womit sie sich die Kritik einiger Slavisten (Tschižewskij), aber das Lob der namhaften Presse einhandelte. ${ }^{50}$ Ähnlich kompetitiv ging es

publikation im Westen gegenübersteht: Boris Chlebnikov, Norbert Franz: Čingiz Ajtmatov, München 1993. Transatlantisch wurde Ajtmatov zunächst als typischer Vertreter des Sozialistischen Realismus rezipiert. Vgl. Katerina Clark: The Mutability of the Canon. Socialist Realism and Chingiz Aitmatov's I dol'she veka dlitsia den', in: Slavic Review 43/4 (Winter 1984), 573-587.

49 Das Archiv des Verlags Volk und Welt enthält eine Pressemappe mit Rezensionen ab 1968.

50 Vgl. das Portrait von Gisela Drohla im Germersheimer Übersetzerlexikon von Natalia Kemper-Bakshi: Art. „Gisela Drohla“ (2016), in: Germersheimer Übersetzerlexikon, hrsg. von Andreas F. Kelletat, Alexey Tashinskiy, online abgerufen abgerufen am 17.04.2021 unter: http://www.uelex.de/artiklar/ Gisela_DROHLA\#_en6 „Der Heidelberger Slavist Dmitrij Tschiževskij, der die Übersetzung selber betreuen wollte, kritisierte die Qualität von Drohlas Übersetzung [...], doch überwog das Lob in den Besprechungen der Frankfurter Allgemeinen Zeitung und der Zeit. Horst Bienek schrieb in der FAZ (5.12.1959): ,Gisela Drohla versuchte, den Intentionen Belyjs zu folgen, seinen Staccato-Sätzen nachzujagen und seine lyrischen Impressionen nachzuempfinden. Das mag mitunter sehr schwierig gewesen sein, denn Belyjs Sprache ist moderner und raffinierter als etwa die Pasternaks. Ihrer 
1960 bei der Übersetzung von Zavist' (dt. Neid) des bis dahin völlig unbekannten sowjetischen Autors der 1920er Jahre, Jurij Oleša, für den Insel-Verlag zu, der im selben Jahr auch bei Goldmann in der Übersetzung von Valerian P. Lebedew erschien. ${ }^{51}$

Auch im Fall von Ajtmatovs Džamilja setzte sich Arnold gegen die ebenfalls interessierte Konkurrenz durch: Arnold berichtete Drohla, daß Louis Aragon die italienische Übersetzung gelesen habe und das Buch für den „schönste[n] Liebesroman der Welt“ halte: „Romeo und Julia und Paolo und Francesca verblassen neben Danijar und Dshamilja.“ ${ }^{\text {"2 }}$ Als er erfuhr, dass Drohla ihre Übersetzung bereits dem Piper-Verlag versprochen hatte, versicherte er ihr telegraphisch, dass sein Verlag ihr dasselbe, ungewöhnlich hohe Honorar zahlen würde. Drohla willigte ein..$^{53}$ Der Roman wurde zum Bestseller und wird bei Insel/Suhrkamp bis heute in unzähligen Auflagen und Ausgaben nachgedruckt, die jüngste 2016 in der Insel-Bücherei (Nr. 2009).

\section{Ajtmatovs Besuch 1968 in Ostberlin und seine Rezeption in der Presse}

Als Ajtmatov im August 1968 nach Berlin und Leipzig kam, war er in der Sowjetunion als Schriftsteller und Literaturfunktionär auf dem ersten Gipfel seiner Karriere angelangt: Seine beiden Bücher, der Erzählband Erzählungen der Steppen und Berge und der Roman Proščaj, Gul'sary! (dt. Leb wohl, Gulsary!) waren mit Staatspreisen (1963 Leninpreis, 1968 Staatspreis für Literatur) ausgezeichnet worden, und seit 1966 war Ajtmatov Mitglied des Obersten Sowjets der UdSSR. In diesen Jahren war er auch ehrenamtliches Mitglied im Redaktionskomitee der wichtigen Literaturzeitschriften Družba narodov (dt.Völkerfreundschaft) und von Novyj mir (dt. Neue Welt). 1968 wurde er schließlich auch zum Volksschriftsteller Kirgisiens ernannt.

Auch im geteilten Deutschland war Ajtmatov kein Unbekannter mehr. Nach Džamilja war gerade auch sein erster Roman, erschienen, und zwar sowohl in der

Übersetzerarbeit sollte man das Lob nicht versagen.' In der Neuen Zürcher Zeitung (4.12.1959) hieß es: ,Es ist erstaunlich, wie weit der Übersetzerin, Gisela Drohla, die Wahrung der sprachlichen Atmosphäre gelungen ist.' Einzelne Kritiker behaupteten, Belyjs Roman sei eine literarische Sensation, sprachlich sehr modern im Sinne von James Joyce oder Alain Robbe-Grillet. Die Übersetzung wurde 1976 von Suhrkamp, zu dem seit 1963 der Insel-Verlag gehörte, ins Hauptprogramm übernommen.“ 2001 erschien Belyjs Roman dann bei Insel in einer neuen Übersetzung von Gabriele Leupold.

51 Für Insel war auch die zweite Publikation eines Romans von Andrej Belyj, nämlich Serebrjanyj golub' (Die silberne Taube), ein Erfolg und brachte Drohla einen langfristigen Vertrag ein.

52 Brief von Arnold an Drohla vom 30.03.1962. Zitiert nach: Kemper-Bakshi (Anm. 50).

53 Vgl. Die Darstellung auf der Seite des Germersheimer Übersetzerlexikons: Kemper-Bakshi (Anm. 50). 
DDR als auch (sogar ein wenig früher) in der BRD. ${ }^{54}$ Sein Besuch 1968 in Ostberlin und Leipzig brachte Ajtmatov - dank einer großen Aufmerksamkeit der Presse - einen sprunghaften Anstieg seines Bekanntheitsgrads in Ostdeutschland. Nach Westberlin kam er damals nicht. Und dem westdeutschen Publikum war er, obwohl bereits zwei Werke in wichtigen Verlagen verlegt worden waren, dank mangelnder Presse - die erste Rezension in der FAZ erschien 1972 - noch wenig bekannt.

Während seines Aufenthalts reiste er zur Präsentation seines gerade im Verlag Kultur und Fortschritt (der jetzt schon Teil des Verlags Volk und Welt war) in der Übersetzung von Leo Hornung erschienen Kurzromans Abschied von Gulsary zur Buchmesse nach Leipzig.

Die zahlreichen Rezensionen zum Buch und zu Ajtmatovs Lesungen (ca. 15) weisen auf die beiden zuvor - ebenfalls bei Kultur und Fortschritt erschienenen - AjtmatovBände hin. Aber die vorhergehende Resonanz in der Presse scheint nicht üppig gewesen zu sein. Jedenfalls wurde aus der Zeit vor 1967 nichts archiviert.

Die Rezensionen zu Abschied von Gulsary! dokumentieren eine umfassende Rezeption in der Hauptstadt- wie in der Kreisstadtpresse, von Seiten der akademischen Slavistik wie von Seiten der Partei. Während etwa eine Rezension in der Parteizeitung Neues Deutschland (16.08.1968) den ausgeprägten Individualismus, die Nichtrelativierung der subjektiven Erzählerperspektive und die karikaturistische Darstellung der Parteifunktionäre kritisiert, würdigt die slavistische Rezension von Nyota Thun im Sonntag (28.07.1968) das weltliterarische Niveau der Erzählung in der Analyse der intertextuellen Auseinandersetzung Ajtmatovs mit Tolstojs Leinwandmesser und Hemingways Der alte Mann und das Meer.

Aus Anlass von Ajtmatovs Aufenthalt in Berlin veröffentlicht die in der DDR für Weltliteratur zuständige Zeitschrift Sinn und Form auch einen Essay Ajtmatovs Verantwortung gegenüber der Zukunft, der 1967 im russischen Original in der wichtigsten literaturwissenschaftlichen Zeitschrift Voprosy literatury erschienen war und programmatisch Ajtmatovs Literaturverständnis zusammenfasst: „Seit jeher erzählt der Mensch vom Menschen. “55 - So lautet der erste Satz. Literatur (Kunst allgemein) als humanum schlechthin, als das, was den Menschen ausmacht. Literatur als Instrument der Erziehung und zugleich der Erkenntnisstiftung, auch für den Autor selbst. Die Geschichte seiner Karriere als Autor mit der jüngsten sowjetischen Literaturgeschichte verflechtend, benennt Ajtmatov seinen Kanon aus russischen und sowjetischen Autoren, inklusive solcher, die erst in der Tauwetterzeit wieder publiziert werden konnten (wie z. B. Bunin). Er kritisiert die Fehlentwicklungen des Stalinismus, ordnet sich selbst ein in die dynamische Entwicklung der jungen Nationalliteraturen (er bezieht sich dabei

54 Die westdeutsche Ausgabe trug in der Übersetzung von Peter Braun den Titel Wirf die Fesseln ab, Gulsary. Erzählung aus einer kirgisischen Kolchose und erschien bei Diederichs (Düsseldorf/Köln 1967). Die ostdeutsche Ausgabe nannte sich Abschied von Gulsary (übers. von Leo Hornung, Berlin 1968).

55 Tschingis Aitmatow: Verantwortung gegenüber der Zukunft, in: Sinn und Form 5 (1968), 1223-1232. 
auf R. Gamzatov, Karim, Kuliev, Kugultinov, nennt den Ukrainer Ivan Drač und den Litauer Justinas Marcinkievicius, die beide schon 1965 in Berlin gewesen waren) und dankt dem kasachischen Mentor Auèzov. Er betont, wie wichtig es ist, nationale Themen und Traditionen mit neuen Entwicklungen der sowjetischen und der Weltliteratur insgesamt zu verbinden, um damit die Internationalisierung der Literatur und die internationale Bedeutung der Literatur als Werkzeug des Humanismus zu fördern. Explizit wird hier, was Ajtmatovs fiktionale Texte sowohl in der Modellierung der Charaktere und ihres Handelns als auch auf der Ebene der intertextuellen Bezüge vorführen: sein Anspruch an die Literatur als Instrument eines universalistischen Humanismus, der die Maximen eines sehr allgemein verstandenen Sozialistischen Realismus hochhält, aber keine Länder- oder Blockgrenzen kennt. Vielleicht ist es kein Zufall, dass im selben Heft von Sinn und Form auch ein Essay über Gor'kij von Leonid Leonov abgedruckt wurde, denn Ajtmatovs Vision von Literatur war zweifelsohne stark von Gor'kij inspiriert, wobei er auf den Gor'kij der Revolutionsjahre und des Verlagsprojekts ,Weltliteratur zurückgriff und damit den von Stalin überzeichneten Gor'kij ausstrich.

Dies lässt sich auch sehr gut in einem Interview erkennen, das Nyota Thun am 21.08.1968 mit ihm in Berlin geführt hat: ${ }^{56} \mathrm{Zu}$ seiner Beziehung zu Kirgisien befragt, nennt Ajtmatov - Gor'kij zitierend - das Epos Manas das ,Schatzkästchen' der kirgisischen Literatur, und zu den Themen seiner Texte befragt, unterstreicht er die auf dem persönlichen Wissen gegründete strikt regionale Ausrichtung, die jedoch stets einherginge mit einem universellen humanistischen Aussageanspruch, der wiederum von nationaler Seite oft kritisch gesehen würde.

AITMATOW: (Seine Antwort fiel knapp aus und wurde von mir höchst unvollständig mitgeschrieben, da diese letzte Frage uns in ein Gespräch verwickelte. Im Zeitungsartikel habe ich sie erst gar nicht erwähnt. Im folgenden wird der Text daher mehr noch aus der Erinnerung, gestützt auf einige Stichpunkte, frei wiedergegeben.) Manas ist tatsächlich eine Schatzkammer unserer Nationalkultur, aus der unsere Schriftsteller schöpfen. Die moderne kirgisische Literatur ist ein Teil der allgemeinen Sowjetliteratur. Sie ist von der russischen Literatur wie von der Weltliteratur stark beeinflußt, vor allem die Prosa. Das führt innerhalb unserer Schriftstellervereinigung zu Konflikten. So wollen mich einige der älteren Autoren nicht als kirgisischen Autor anerkennen, da ich meine literarischen Texte seit Goldspur der Garben gleich in russischer Sprache verfasse. Die Spannungen vertieften sich nicht nur durch den Bruch mit rein künstlerischen Traditionen, insbesondere auf dem Gebiet des Sprachstils, sondern nicht minder durch den offenen Bruch mit jahrhundertealten Bräuchen und Sitten in einigen meiner Erzählungen wie Djamila und Du meine Pappel im roten Kopftuch. Vor allem der von mir als Befreiung geschilderte Ausbruch der Frau aus den traditionellen Bindungen im Familienverband stieß auf harten Widerstand, bis heute. [...]

AITMATOW: Jeder Künstler ist - obwohl wir sagen, daß er besonders veranlagt ist und auf seine Weise etwas ausdrückt - eine Stimme seiner Umwelt. Wie originell und selbständig er auch immer sein will, er ist die Stimme der Umwelt, in der er aufgewachsen und geistig herangereift ist und in der er seine Lebenserfahrungen gesammelt hat. Jeder ernsthafte Künstler schreibt nur über das,

56 Mein großer Dank geht an Franziska Thun-Hohenstein, die mir die von Nyota Thun aufgezeichneten und transkribierten Interviews zur Verfügung gestellt hat. 
was er sehr gut kennt und was ihn bewegt, nur das, wozu er zu schreiben fähig ist. Ein Beispiel. Ich bin nach Berlin gekommen. Hier ist alles interessant. Ich habe viele Eindrücke, Aber ich hätte nicht den Mut, auch nur eine kleine Erzählung über Ihr Leben zu schreiben. Vielleicht einen Artikel. Aber das ist schon etwas anderes. Wenn wir jedoch von der Beziehung eines Autors zu seinem Werk sprechen, zum Konflikt, den er gestalten und lösen will, so ist es nicht zufällig nicht nur der subjektive Wille des Autors, daß er darüber schreibt. Hierfür gibt es auch einige objektive Gründe. Ich als Autor verstehe die große Verantwortung für das, was ich darstellen wollte.

\section{Die Ajtmatov-Rezeption im Westen}

Im Westen wurde Lebwohl, Gulsary! ebenfalls 1968, hier unter dem Titel Wirf die Fesseln $a b$, Gulsary, beim Diederichs Verlag in einer eigenen Übersetzung und noch vor der Publikation in der DDR publiziert. ${ }^{57}$ Aber nach Westdeutschland wurde Ajtmatov, der bereits in den frühen 1960er Jahren, nach der französischen Publikation von Džamilja, auf Einladung von Aragon Paris besucht hatte, damals noch nicht eingeladen. Auch die westdeutsche Presse kannte Ajtmatov noch nicht. Dazu brauchte es noch einen weiteren Schritt: nämlich den über das Vorwort von Louis Aragon zu Džamilja, das ja bereits 1962 die Motivation für die westdeutsche Publikation bei Insel verstärkt hatte. Aber publiziert war es in deutscher Übersetzung ebenso wenig wie auf Russisch. Erst als 1972 der Suhrkamp Verlag beschloss, Džamilja in die Bibliothek Suhrkamp aufzunehmen und bei dieser Gelegenheit auch das Vorwort publizierte, wurde auch die westdeutsche Presse auf Ajtmatov aufmerksam. Und schon die erste Rezension von Kay Borowski, ${ }^{58}$ die 1972 in der FAZ erschien, ordnete Ajtmatovs Erzählung durch einen Vergleich mit Goethe direkt in den Kanon der großen Klassiker der Weltliteratur ein:

„Wem die Natur ihr offenbares Geheimnis zu enthüllen anfängt, der empfindet eine unwiderstehliche Sehnsucht nach ihrer würdigsten Auslegerin, der Kunst.“ - sagt Goethe, und Aitmatow: „Selbst heute noch stelle ich mir oft die Frage, ob die Liebe nicht eine Inspiration ist wie die Inspiration des Malers, des Dichters.“ [...] Das unauffällig kunstvolle kleine Werk ist nie effektvolle Manier, sondern reiner Stil, der nach Goethe „,auf den tiefsten Grundfesten der Erkenntnis, auf dem Wesen der Dinge ruht. “59

57 Tschingis Ajtmatow: Wirf die Fesseln ab, Gulsary. Erzählung aus einer kirgisischen Kolchose, übers. von Peter Braun, Düsseldorf/Köln: 1967.

58 Der Slavist promovierte damals gerade noch in Tübingen über Pasternak.

59 Kay Borowski: Dshamilja. Eine kirgisische Liebesgeschichte, in: Frankfurter Allgemeine Zeitung (29.06.1972). 


\section{Aragons Vorwort zu Džamilja - Misreading mit starkem Effekt}

Abschließend möchte ich noch einen Blick auf Louis Aragons Vorwort zu Džamilja werfen, das ebenfalls eine weltliterarische Einordnung vorgenommen und damit die nationale und internationale Rezeption von Ajtmatov so stark beeinflusst hat.

Aragon eröffnet seinen Text mit einem interessanten Vergleich. Rudyard Kiplings Erzählung The Finest Story in the World $(1891)^{60}$ hätte ihn auf die Idee des Titels gebracht. ${ }^{61}$ Es sei ein negativer Vergleich, denn der Selbstempfehlung Kiplings hätte er, Aragon, nie über den Weg getraut. Was Aragon nicht erklärt, ist viel interessanter: Bei Kipling und bei Ajtmatov geht es um die Beziehung von Liebe und künstlerischem Schaffen. Bei Kipling sind künstlerische Kreativität und Liebe einander - im Sinne der Psychoanalyse - entgegengesetzt. Bei dem Protagonisten, einem indischen jungen Mann, der an Reinkarnation glaubt, resultiert der Drang, Erzählungen zu schreiben, aus einer unheimlichen Besessenheit von der Vergangenheit. Diese kann und wird schließlich durch die Liebe zu einer Frau ,geheilt‘. In Ajtmatovs Erzählung dagegen ist die Relation genau umgekehrt: Die Liebe ist die Initiation und der Quell des künstlerischen Schaffens. Und dessen wichtigstes Thema und wichtigste Aufgabe ist das Bewahren der Grundwerte des Menschen - genannt: Humanismus - durch Erinnerung und Bewahren der eigenen Wurzeln und Erfahrungen.

Aragons stellt mit seinem Vergleich indirekt die ,sowjetisch-orientalische‘ Erzählung des kirgisischen Newcomers über die orientalistische Erzählung des britischen Klassikers. Nachfolgend jedoch schlägt Aragon eine andere Richtung ein: Er vergleicht die Liebesgeschichte aus dem unbekannten Land im unbekannten Zentralasien mit sämtlichen berühmten Liebesgeschichten der europäischen Weltliteratur und bewertet sie als „,noch schöner“ als letzt, was er - wiederum indirekt - mit ihrer Naivität begründet. Und damit exotisiert er selbst im Grunde Ajtmatovs Erzählung: Die „außerordentliche Leichtigkeit ihres Erzählflusses“ stehe im Gegensatz zu der „,an der Reportagekrankheit leidenden Literatur“ der Moderne. Einerseits ist diese Gegenüberstellung unschwer als Anspielung auf György Lukács zu erkennen, der im sowjetischen Exil zum Propagator des Sozialistischen Realismus geworden war und unter dem Stichwort ,Reportage“ nicht nur den Naturalismus, sondern die erzählerische Moderne insgesamt kritisierte, der er den historischen Realismus und dessen Wiederbelebung im Zeichen des Sozialismus gegenüberstellte. ${ }^{62}$

60 Rudyard Kipling: The Finest Story in the World, in: Contemporary Review (July 1891), 9-31. 61 Louis Aragon: Die schönste Liebesgeschichte der Welt, in: Tschingis Aitmatov: Dshamilja, Frankfurt a. M. 1972, 7-20.

62 Vgl. Georg Lukács: Reportage oder Gestaltung? Kritische Bemerkungen anlässlich des Romans von Ottwalt, in: Die Linkskurve, 4/7 (1932), 23 ff. und 4/8 (1932), 27 f., zitiert nach: Georg Lukács: Werke, Bd. 4: Essays über Realismus, Neuwied/Berlin 1971, 35-68. 
Andererseits wird Ajtmatov von Aragon dadurch aber nicht so sehr in den Kontext des Sozialistischen Realismus gerückt, sondern vielmehr in den der in die europäische Moderne eingegliederten ,Naiven':

Das Kind Said, das hier spricht, steigt nicht aufs Katheder, um einen ethnologischen Vortrag oder eine politische Vorlesung zu halten. Es ist hier geboren, alles ist ihm natürlich, die Nomadenzeit hat es nicht mehr erlebt, zwei oder drei Jahre vor seiner Geburt muß sie aufgehört haben, aber die Mutter stellt noch jedes Frühjahr die Nomadenjurte im Hof auf, die der Vater als junger Mann gebaut hatte, und räuchert sie mit Wacholder aus. ${ }^{63}$

Die Unschuld und Unbefangenheit dieses Erzählens fürchtend, das dem ,erschöpften Westen' wie ein ,verlorenes Paradies‘ erscheint, vergleicht Aragon Ajtmatov mit dem Zöllner Rousseau und zieht eine Verbindung zwischen dem Maler, der als naiver Amateur einen Platz im Kanon der Moderne gefunden hat, und dem traditionellen kirgisischen Epos Manas - von dem Aragon zu diesem Zeitpunkt nur aus den Hinweisen in der Erzählung selbst wissen konnte. Ohne zu bedenken, dass Ajtmatov keineswegs Amateur war, sondern ein Literaturstudium am Gor'kij-Institut absolviert hatte und in vollem Bewusstsein des Literaturraums schrieb, in dem er agierte und sich positionieren wollte, fürchtet Aragon um die ,Unschuld‘ des naiven Chef d'oeuvre:

Ich habe Angst, daß die Schule und die Malakademie sein Talent verderben, ihn jene erzählerische Tugend in der Zeichnung und in den Farben verlieren lassen, die sowohl etwas vom Zöllner Rousseau als vom Epos des Manasa haben mußten, jene Unbefangenheit, die die Maler der erschöpften alten Kulturen des Westens wiederzufinden versuchen wie den Weg zu einem verlorenen Paradies. ${ }^{64}$

Schließlich mündet Aragons Charakterisierung in einen an Pathos kaum zu übertreffenden Hymnus, der wieder unschwer als Invektive gegen Moderne, künstlerische Selbstreflexivität und abstrakte Kunst erkannt werden kann:

Mein Gott, wie ist die Welt noch jung und schön! Wie ist noch nichts ausgeschöpft, wie kann alles noch das Herz der Menschen höher schlagen lassen! Es gibt Leute, die sich dafür, daß sie leben, entschuldigen wollen mit einer gelehrten Musik, aus der alle wirkliche Musik verbannt ist, damit das Wesen der Musik umso deutlicher würde. Es gibt Leute, die einen Punkt des Wissens erreichen, wo Wissen nur noch Spiel ist. Es gibt Leute, die sich damit erschöpfen, sich im Spiegel nicht ähnlich zu sehen ... Und dann gibt es am Ufer des Kukureu zwischen China und Tadshikistan einen Jungen, der vor dreißig Jahren ein Dschigit wie die anderen geworden wäre und der seine Augen zu uns wendet und spricht, und man will nur noch schweigen und ihm zuhören.

Ich danke Gott, an den ich nicht glaube, für diese Augustnacht, an die ich glaube mit meinem ganzen Glauben an die Liebe.

Paris, 30. März 1959 Louis Aragon ${ }^{65}$

63 Aragon: Liebesgeschichte (Anm. 61), 12.

64 Ebd., 16.

65 Ebd., 20. 
In der Sowjetunion ist Aragons Einleitung nie erschienen. Nur Aragons knalliger Titel wurde 1961 auf einer Themenseite der Literaturnaja gazeta - „Džamilja und die internationale Presse“ - verwendet. Dort erschien ein Auszug aus einem anderen, ursprünglich in den Lèttres françaises publizierten Artikel von Aragon, in dem er Džamilja als „Zeugnis dafür [anführt], dass nur der Realismus über die Liebe erzählen kann“. ${ }^{66}$ Obwohl es also (in der BRD) spät und in der DDR wie in der Sowjetunion gar nicht gedruckt wurde, hatte Aragons Vorwort de facto größten Einfluss auf die sowjetische und die westliche Rezeption und erzielte einen Rückkopplungseffekt zwischen beiden, der so lange anhielt, wie die Sowjetunion bestand, und im Fall von Džamilija sogar darüber hinausging. Nach 1991 gingen die Rechte an Ajtmatovs in der DDR übersetzten Texten an den Schweizer Unionsverlag, der schon seit 1987 Texte von Ajtmatov in Übersetzungen von Friedrich Hitzer ${ }^{67}$ publizierte, wo sie bis heute erfolgreich in Neuauflagen erscheinen. ${ }^{68}$ Auch Džamilja erscheint dort in regelmäßigen Neuauflagen in der DDR-Übersetzung von Hartmut Herboth, während die Erzählung in ebenso ungezählten Neuauflagen bei Suhrkamp weiterhin in der Übersetzung von Gisela Drohla und stets mit Aragons Vorwort gedruckt wird.

66 Vgl. wörtlich: „[...] чтобы маленькая книжка Айтматова стала свидетельством того, что лишь реализм способен рассказать историю любви. [...] Ибо любовь [...] должна быть реальной, как и реалистическим должно быть искусство [...] Есть опасность, что мне скажут: Ваши реалисты это прежде всего люди Востока [...] Да, именно сказки тысячи и одной ночи возвращаются к нам под звездным знаменем социализма, а ведь это и есть Восток!“ Louis Aragon, übers. aus: Lèttres françaises 768 (1959), Literaturnaja gazeta 23.03.1961.

67 Hitzer avancierte ab den 1980ern zu Ajtmatovs Leibübersetzer und Dolmetscher, der auch den Diplomaten Ajtmatov durch die Welt begleitete.

68 Eine gute Übersicht über die verschiedenen Ausgaben bietet Friedrich Hübners nützliche kommentierte Zusammenstellung Russische Literatur des 20. Jahrhunderts in deutschen Übersetzungen, Köln 2012. 